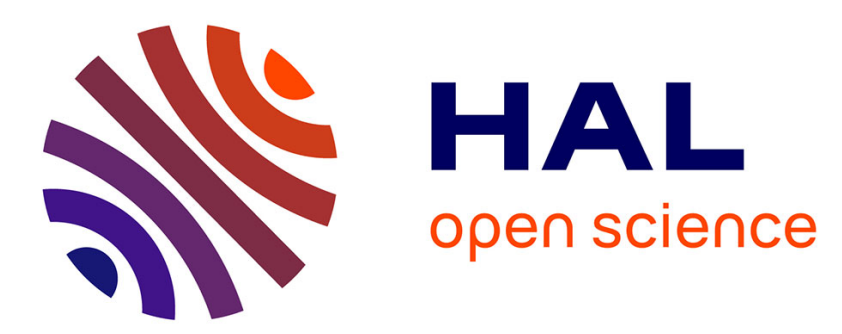

\title{
De recensement en recensement, le devenir professionnel des ouvriers et employés
}

Alain Chenu

\section{To cite this version:}

Alain Chenu. De recensement en recensement, le devenir professionnel des ouvriers et employés. Economie et Statistique / Economics and Statistics, 1998, 316-317, pp.127 - 149. hal-01499365

\section{HAL Id: hal-01499365 \\ https://hal-sciencespo.archives-ouvertes.fr/hal-01499365}

Submitted on 31 Mar 2017

HAL is a multi-disciplinary open access archive for the deposit and dissemination of scientific research documents, whether they are published or not. The documents may come from teaching and research institutions in France or abroad, or from public or private research centers.
L'archive ouverte pluridisciplinaire HAL, est destinée au dépôt et à la diffusion de documents scientifiques de niveau recherche, publiés ou non, émanant des établissements d'enseignement et de recherche français ou étrangers, des laboratoires publics ou privés. 


\section{De recensement en recensement, le devenir professionnel des ouvriers et employés}

Alain Chenu *

* Alain Chenu, professeur de sociologie, est membre du Laboratoire de sociologie quantitative (CREST). II a réalisé cette étude grâce au soutien de la division Enquêtes et études démographiques de l'Insee.

Les noms et dates entre parenthèses renvoient à la bibliographie en fin d'article.

Un ouvrier ou employé sur sept accédait à un emploi salarié de cadre ou de membre des professions intermédiaires de 1982 à 1990, contre un sur dix de 1968 à 1975. Sur ces deux périodes, le taux de passage à son compte, comme artisan, commerçant ou chef d'entreprise, reste le même (un sur trente). Cette mobilité professionnelle ascendante plus intense est en rapport direct avec l'élévation des niveaux de formation. Cependant, dans le même temps, les risques de chômage ont été multipliés par trois. La part des ouvriers et employés promus ou licenciés est passée de $15 \%$ au terme de la période 1968-1975 à $25 \%$ pour 1982-1990 : les emplois de salariés peu qualifiés semblent bien constituer des positions de plus en plus instables.

Les femmes accèdent deux fois moins que les hommes à des catégories supérieures, et leur risque de chômage est presque double. Ce handicap s'atténue légèrement en matière de promotions, mais persiste en termes de chômage.

Les générations nées pendant la seconde guerre mondiale ont été, dans l'ensemble, plus favorisées que les plus anciennes et les plus récentes. Les promotions interviennent à des âges de plus en plus élevés.

$\mathrm{P}$ rès des deux tiers des emplois relèvent du groupe socioprofessionnel des ouvriers ou de celui des employés. Tantôt ils sont occupés par des personnes durablement ancrées dans une condition de salarié peu qualifié, tantôt ils constituent des étapes au long de carrières aboutissant à d'autres positions professionnelles. Certaines caractéristiques, et tout d'abord un niveau élevé de formation, facilitent les sorties « par le haut » d'une position d'ouvrier ou d'employé. D'autres, à l'inverse, renforcent les risques de chômage auxquels les salariés peu qualifiés sont exposés. Quels sont les effets de l'âge et de la génération sur les carrières ? Les années 80 ont-elles été plus (ou moins) favorables aux promotions que les années antérieures? Habiter à la campagne, dans une petite, une grande ville de province ou l'agglomération parisienne confère-t-il un avantage ou un handicap en matière de promotion, de mise à son compte, d'exposition au chômage ? Quels secteurs d'activité offrent des carrières faciles, lesquels se révèlent des impasses ? Les chances des célibataires, des étrangers sont-elles meilleures que celles des couples mariés, des Français? 
L'échantillon démographique permanent (EDP) permet d'apporter à de telles questions des réponses statistiquement solides. Il est le seul panel (dispositif longitudinal grâce auquel les mêmes personnes sont observées à plusieurs reprises) qui se caractérise par un taux de sondage important ( $1 / 100$ environ), concerne l'ensemble de la population résidant sur le territoire de la France métropolitaine et fasse appel, sur une période de vingt-deux ans jalonnée par quatre recensements de la population (1968 à 1990), à un même ensemble de nomenclatures, notamment une nomenclature unique de catégories socioprofessionnelles (Sautory, 1987 ; Chenu, 1992 et 1993b ; Rouault, 1995).

\section{Étudier les changements de situation d'un recensement à l'autre}

Au terme de chacune des trois périodes intercensitaires de sept ou huit ans observées grâce à ce dispositif (1968-1975, 1975-1982, 19821990), on choisit ici de décrire le devenir des personnes occupant initialement des emplois d'ouvriers ou d'employés. Les ouvriers agricoles sont exclus, étant peu nombreux et présentant de fortes spécificités. Une telle délimitation permet de prendre en compte une très grande partie de la population, en faisant porter l'analyse sur un ensemble d'une relative homogénéité, composé de salariés occupant des

Tableau 1

Le devenir des ouvriers et employés au terme de trois périodes intercensitaires

Taux bruts

\begin{tabular}{|c|c|c|c|c|}
\hline & & & \multicolumn{2}{|r|}{ En \% } \\
\hline & & $1968-1975$ & $1975-1982$ & $1982-1990$ \\
\hline \multirow[t]{6}{*}{ Ensemble } & Taux de promotion (1) & 9,3 & 10,1 & 13,8 \\
\hline & Taux de mise à son compte (2) & 3,4 & 3,3 & 3,3 \\
\hline & Promotion ou mise à son compte & 12,7 & 13,4 & 17,2 \\
\hline & Chômage (3) & 2,2 & 5,7 & 7,5 \\
\hline & Effectif EDP (4) & 74241 & 82987 & 82801 \\
\hline & Part des ouvriers et employés (5) & 68,6 & 66,1 & 63,1 \\
\hline \multirow[t]{3}{*}{ Hommes } & Taux de promotion & 10,4 & 11,6 & 15,0 \\
\hline & Taux de mise à son compte & 4,0 & 4,4 & 4,5 \\
\hline & Promotion ou mise à son compte & 14,4 & 16,0 & 19,5 \\
\hline \multirow[t]{3}{*}{. } & Chômage & 1,7 & 4,8 & 5,9 \\
\hline & Effectif EDP (4) & 50511 & 51681 & 47374 \\
\hline & Part des ouvriers et employés & 67,2 & 63,1 & 59,0 \\
\hline \multirow[t]{7}{*}{ Femmes } & Taux de promotion & 6,9 & 7,6 & 12,3 \\
\hline & Taux de mise à son compte & 2,1 & 1,6 & 1,8 \\
\hline & Promotion ou mise à son compte & 9,0 & 9,2 & 14,1 \\
\hline & Chômage & 3,3 & 7,3 & 9,7 \\
\hline & Taux de passage au foyer (6) & 21,6 & 17,3 & 12,0 \\
\hline & Effectif EDP (4) & 23730 & 31306 & 35427 \\
\hline & Part des ouvrieres et employées & 71,6 & 71,1 & 68,7 \\
\hline \multicolumn{5}{|c|}{$\begin{array}{l}\text { 1. Nombre d'ouvriers-employés devenus cadres ou membres des professions intermédiaires en fin de période sur l'ensemble des } \\
\text { ouvriers-employés en début de période et encore en emploi en fin de période. } \\
\text { 2. Nombre d'ouvriers-employés devenus artisans, commerçants ou chefs d'entreprise en fin de période sur l'ensemble des ouvriers- } \\
\text { employés en début de période et encore en emploi en fin de période. } \\
\text { 3. Nombres d'ouvriers-employés au chômage en fin de période sur l'ensemble des ouvriers-employés en début de période et encore } \\
\text { en emploi en fin de période. } \\
\text { 4. Nombre d'ouvriers-employés occupés en début de période et encore en emploi en fin de période, en unité. } \\
\text { 5. Part des ouvriers et employés en début de période dans l'ensemble des actifs occupés en début de période et encore en emploi } \\
\text { en fin de période. } \\
\text { 6. Nombre de femmes devenues "femmes au foyer " en fin de période sur l'ensemble des ouvrières et employées en début de pé- } \\
\text { riode et encore en emploi en fin de période. }\end{array}$} \\
\hline
\end{tabular}

Source : Échantillon démographique permanent, Insee. 
emplois subalternes requérant, en principe, un niveau de formation inférieur au baccalauréat. Dans cet ensemble, la féminisation et la tertiarisation des emplois se traduisent par une progression de la part des employés au détriment de celle des ouvriers : la part des employés passe de $35.5 \%$ en $1968-1975$ à $40,5 \%$ en 1975-1982 et 47,6\% en 1982-1990. Le poids des ouvriers et employés tend à diminuer au profit de catégories plus qualifiées, mais reste très fort : il passe de $69 \%$ du total des emplois en 1968 à $63 \%$ en 1982 (cf. tableau 1). Le choix de s'intéresser ici aux destinées des personnes occupant de tels emplois, plutôt qu'aux recrutements, résulte da ce qu'au long des vies professionnelles, les emplois d'ouvriers et d'employés sont des positions de départ bien plus souvent que des positions d'arrivée (1).

Quatre destinées des ouvriers et employés sont étudiées ici : 1'accès à un emploi de cadre ou à une profession intermédiaire, la mise à son compte comme artisan, commerçant ou chef d'entreprise, le chômage, et enfin, pour les femmes, l'accès au statut de femme au foyer. La mise à son compte, en tant qu'artisan, commerçant ou chef d'entreprise, est définie de manière restrictive, en excluant le statut d'aide familial. Les départs en retraite, les décès, l'émigration ne sont pas retenus; d'où une limitation, en termes d'âge, aux personnes ayant au moins seize ans en début de période et au plus soixante-cinq ans en fin de période.

L'analyse porte sur l'effet, sur ces destinées, d'une série de caractéristiques sociales ou démographiques, individuelles ou contextuelles. renseignées lors des recensements de la population (cf. encadré 1). Le souci de comparer les trajectoires féminines et masculines est constamment présent. La technique statistique retenue est la régression logistique, qui vise à raisonner «toutes choses égales par ailleurs »: elle consiste, par exemple, à comparer le devenir des Parisiens et des provinciaux en prenant en compte le fait que, dans l'ensemble, les premiers détiennent plus de diplômes, sont plus souvent célibataires ou divorcés, travaillent plus dans le secteur tertiaire, etc., que les seconds. Une telle démarche, qui tend à faire abstraction des effets de structure, relève pour une part de la fiction. À bien des égards, le Parisien et le provincial sont irréductibles l'un à l'autre. Dans la mesure, cependant, où ils s'inscrivent dans un même monde social, ils peuvent faire l'objet d'une description selon des variables communes. Il s'agit non de prétendre épuiser la liste des ressemblances et différences entre des catégories, mais d'en proposer un inventaire partiel.

Les calculs de régression sont effectués pour chacune des trois périodes intercensitaires considérées et sur un fichier de périodes dans lequel les individus statistiques ne sont plus des personnes physiques mais des individus-périodes :

1. Ainsi parmi les personnes nées entre 1942 et 1948 , présentes aux quatre recensements et en emploi en 1968, la part des ouvriers et employés était de $77 \%$ en 1968 (à 23 ans environ), $55 \%$ en 1975 (à 30 ans), $47 \%$ en 1982 (à 37 ans) et $43 \%$ en 1990 (à 45 ans). Pour les générations nées entre 1935 et 1941, les chiffres correspondants étaient de $61 \%$, $48 \%, 42 \%$ et $36 \%$.

\section{Encadré 1}

\section{LES DIMENSIONS DE L'ANALYSE}

\section{Variables dépendantes}

La promotion est définie comme l'accès à un emplo de cadre ou de membre des professions intermédiaires (catégories 3 et 4 de la nomenclature des professions et catégories socioprofessionnelles : CS 3 et 4), la mise à son compte comme l'accès à un emploi d'artisan, commerçant ou chef d'entreprise (CS 2), les personnes travaillant sous un statut d'aide familial étant exclues. Les définitions du chômage et du foyer sont celles du recensement de la population.

\section{Délimitation de la population}

On s'intéresse aux personnes qui, en début de période, sont employés ou ouvriers (CS 5 et 6 ) en emploi hors du secteur agricole et âgées de 16 à 57 ans. La délimitation en fin de période varie selon les cas : population en emploi pour l'étude des promotions et des mises à son compte, population active pour celle du chômage, population active ou au foyer (à l'exclusion des retraitées) pour l'étude des passages au foyer.

\section{Variables explicatives}

Trois variables "explicatives ", la mobilité, la catégorie socioprofessionnelle et le secteur d'activité économique, sont mises en œuvre à deux niveaux de détail, le plus agrégé dans les tableaux 3 à 7 et dans l'annexe I, le plus détaillé dans l'annexe II.

Âge: le choix de tranches d'âge de sept ans se prête à l'étude des effets d'âge et des effets de période, puisque les recensements se succèdent de sept ans en sept ans (huit pour la période 1982-1990). 
Encadré 1 (fin)

Diplôme : on distingue quatre grands niveaux : sans diplôme ou sans réponse, certificat d'études primaires ou équivalent, CAP-BEP ou équivalent, diplômes plus élevés. L'effet de cette variable sur les itinéraires sociaux et professionnels étant très important, it serait souhaitable de disposer d'une nomenclature plus fine ; mais, au recensement, la qualité de l'information la concernant est assez médiocre (Bégué, 1971 ; Sautory, 1988). Les appariements réalisés pour constituer l'échantillon démographique permanent (EDP) permettent de remédier, en partie, à la fréquence des non-réponses aux recensements : on retient ici le niveau de diplôme le plus élevé, observé soit en début, soit en fin de période intercensitaire.

Situation matrimoniale : on distingue les catégories juridiques de célibataire, marié, veuf ou divorcé. Cette variable ne figure pas aux tableaux 3,5 et 7 , en raison de sa forte interaction avec la variable sexe (le mariage a sur les carrières des effets inverses pour les hommes et pour les femmes).

Mobilité géographique et mobilité de l'emploi: l'étude étant centrée sur les appartenances professionnelles, la mobilité géographique est définie par un changement de département de travail entre deux recensements (cf. tableaux $3,5,7$ et annexe I). Lorsque l'information sur le lieu de travail fait défaut (soit une fois sur cinq environ), on se réfère au lieu de résidence.

Dans l'annexe II, on croise mobilité géographique et mobilité de l'emploi et on distingue 5 types de mobilités : pas de changement d'établissement entre deux recensements, changement d'établissement sans modification de secteur et de département, changements d'établissement et de secteur sans modification de département, changements d'établissement et de département sans modification de secteur et enfin changements d'établissement, de secteur et de département.

Ces distinctions ne s'appliquent pas à l'étude des parcours des personnes aboutissant au chômage ou à une situation de femme au foyer. Elles sont rendues possibles par la présence, dans le fichier de l'EDP, de la variable " changement d'établissement " renseignée par un traitement manuel spécifique. En 1990, ce traitement n'a été effectué que pour la moitié des bulletins (1). Quand le nom de l'établissement a changé mais pas l'adresse, on considère qu'il y a maintien dans le même établissement : ceci peut correspondre à un changement de raison sociale sans mobilité effective de l'emploi ; il s'agit donc d'une acception extensive de la stabilité.

Secteur d'activité économique: Pour les tableaux 3 , 5,7 et l'annexe I, on distingue seulement secteur industriel et secteur tertiaire. Dans l'annexe II, deux grilles plus fines, établies séparément pour les hommes et pour les femmes, ont été constituées en fonction des exigences suivantes : assurer une correspondance optimale entre la nomenclature des activités économiques, seule disponible pour 1968 , et la nomenclature des activités et des produits, disponible pour les trois recensements ultérieurs ; comporter des effectifs suffisants par classe et présenter une certaine homogénéité sociologique. On distingue, autant que possible, les secteurs à forte composante de petites entreprises et les secteurs à dominante d'emploi salarié. Dans les premiers, changer de statut pour les ouvriers et employés consiste, assez souvent, à se mettre à son compte ; dans les seconds, les carrières se situent au sein du monde salarié et aboutissent à des positions d'agents de maîtrise, techniciens ou cadres (Chenu, 1992).

Nationalité : on distingue les Français de naissance, les Français par acquisition et les étrangers (nationalité en début de période).

Catégorie socioprofessionnelle : les employés qualifiés regroupent les catégories socioprofessionnelles 52 à 54 de la nomenclature, les employés non qualifiés les catégories 55 et 56 , les ouvriers qualifiés les catégories 62,63 et 65 et les ouvriers non qualifiés les catégories 64,67 et 68 . Pour les ouvriers, le regroupement diffère de celui habituellement retenu par l'Insee : les chauffeurs (CS 64) sont considérés comme non qualifiés, les niveaux de diplôme, risques de chômage et perspectives de promotion de cette catégorie ne justifiant pas leur assimilation aux ouvriers qualifiés.

Dans l'annexe II, on distingue, pour les hommes, les employés (CS 5) et chacune des six catégories d'ouvriers, pour les femmes, les employées de la Fonction publique (CS 52 et 53 ), les employées administratives d'entreprise (CS 54), les employées de commerce (CS 55), les personnels des services directs aux particuliers (CS 56) et les ouvrières (CS 6 sauf 69$)$.

Sexe : il figure comme régresseur aux tableaux 3,5 et 7. Dans les annexes I et II, hommes et femmes font l'objet d'analyses distinctes.

Tranche d'unité urbaine: on distingue quatre modalités: communes rurales, unités urbaines de moins de 100000 habitants, unités urbaines de 100000 à 2 millions d'habitants et agglomération parisienne (lieu en début de période).

1. La mobilité apparente, notamment entre 1982 et 1990 , est, en partie, imputable aux changements de procédures de codage, indépendamment des changements renseignés par les personnes recensées. Les bulletins de 1968 à 1982 ont fait l'objet d'un codage manuel spécifique à l'EDP. En 1990, les bulletins des individus membres du panel ont été intégrés dans le "quart lourd " d'exploitation du recensement : seules quelques variables (changement de profession et d'établissement) ont donné lieu à un codage spécifique. Pour 1990, de nombreuses variables ne sont disponibles que sous forme redressée (les "sansréponses " ont été remplacées par des valeurs aléatoires, selon la méthode hot deck). Pour les autres années, les valeurs non redressées sont disponibles et ont été utilisées chaque fois que possible. 
une même personne peut être présente trois fois dans le fichier, si elle figure dans l'EDP des quatre recensements et si elle était classée comme employé ou ouvrier en 1968, 1975 et 1982.

Unc limite d'une telle approche tient aux changements qui affectent au fil du temps la signification de l'appartenance à tel ou tel groupe socioprofessionnel. En effet, un groupe statistique est un ensemble en mouvement. Être ouvrier ou cadre n'a pas la même signification en 1968 et en 1990. Les ouvriers relèvent de plus en plus souvent du secteur tertiaire (Chenu, 1993a), les cadres, plus nombreux, forment une catégorie en voie de banalisation. Les écarts de salaires entre ces deux groupes socioprofessionnels se sont réduits puis stabilisés (cf. tableau 2). Certaines évolutions seront prises en compte dans l'analyse (par exemple, la tertiarisation de l'emploi ouvrier), d'autres ne le peuvent, tel le salaire qui n'est pas renseigné lors des recensements de la population.

\section{Une instabilité accrue dans les années 80}

$\mathrm{L}$ es promotions comme cadre ou membre des professions intermédiaires sont sensiblement plus fréquentes de 1982 à 1990 qu'au cours des périodes précédentes (cf. tableau 1); leur taux brut, de $9 \%$ pour la période 19681975 et de $10 \%$ en $1975-1982$, atteint $14 \%$ en 1982-1990. L'écart important au profit de la dernière période ne résulte pas seulement du fait que celle-ci est longue de huit ans et non de sept. Le questionnement rétrospectif des enquêtes Formation-qualification professionnelle $(F Q P)$, qui permettent de caractériser la mobilité professionnelle au terme de périodes de cinq ans, aboutit à des observations concordantes (cf. encadré 2).

Les taux de mise à son compte varient très peu : en sept ans, un ouvrier ou employé sur trente devient employeur ou indépendant. Les risques de chômage ont plus que triplé de la première à la troisième période. Les vies professionnelles féminines sont de plus en plus continues : en 1968-1975, plus d'une femme sur cinq quittait la population active pour devenir « femme au foyer », une femme sur huit seulement fait de même en 1982-1990.

L'instabilité de la condition de salarié peu qualifié s'est donc accrue, sous le double effet de la montée du chômage et de l'amélioration des chances de promotion. Les changements postérieurs à 1982 sont plus amples que ceux qui sont intervenus entre les deux premières périodes intercensitaires.

Les taux nets, calculé « toutes choses égales par ailleurs » (2), de promotion s'accroissent de période en période (cf. quatrième colonne du tableau 3 et graphique I). Pour un taux net de

2. Les taux calculés s'obtiennent à partir des coefficients $\beta_{i}(-0,063$ et 0,257$)$ figurant à la colonne " 3 périodes " du tableau 3, aux lignes 1968-1975 et 1982-1990. $p_{i}=1 /\left[1+e^{\left(-\alpha-\beta_{1}\right)}\right]$. Ici $\alpha=\log [10,1 /(100-10,1)]$. Pour $1968-1975,9,5=100 /\left[1+e^{[-\log (10,1 /(100-10,1)-(-0.063)]}\right]$.

Tableau 2

Indices de salaires moyens

Base $100=$ ouvriers

\begin{tabular}{|l|c|c|c|}
\hline \multirow{2}{*}{} & \multicolumn{2}{|c|}{ Catégories socioprofessionelles (1) } \\
\cline { 2 - 4 } & Cadres supérieurs & Cadres moyens & Employés \\
\hline 1968 & 442 & 210 & 110 \\
1975 & 374 & 183 & 106 \\
1982 & 313 & 166 & 106 \\
\hline & Cadres et professions & Professions intermédiaires & Employés \\
& intellectueles supérieures & 162 & 105 \\
\hline 1984 & 279 & 152 & 100 \\
1991 & 277 & \multicolumn{2}{|c|}{} \\
\hline 1. Catégories socioprofessionnelles (CSP) : code en vigueur de 1954 à 1982. \\
Professions et catégories socioprofessionnelles (PCS) : code en usage depuis 1982.
\end{tabular}

Champ : salariés à temps complet des déclarations annuelles de données sociales (DADS).

Source : Bayet et Julhès, 1996 
3. Les discontinuités d'une nomenclature de diplômes à quatre niveaux conduisent à une sous-estimation des effets de cette variable sur les phénomènes étudiés. promotion de $10 \%$ observé au terme de la période centrale 1975-1982, le taux net est de $9,5 \%$ pour les années $1968-1975$, et de $13 \%$ pour 1982-1990, soit un taux de $11 \%$ si l'on ramène la durée de la dernière période à sept ans. Cette progression est moins forte que celle des effets bruts qui partent, eux, de $9 \%$ en 1968 1975 pour atteindre $14 \%$ en 1982-1990 : l'évolution de ces derniers exprime notamment l'amélioration des niveaux de formation, un « effet-qualité » dont il est fait abstraction, pour l'essentiel (3), dans le calcul des effets nets. La féminisation joue, à l'inverse, dans le sens d'une baisse des taux de promotion, plus que compensée par la progression des niveaux de diplôme.

\section{Des promotions de plus en plus tardives}

C'est toujours aux âges intermédiaires que les promotions sont plus fréquentes, mais d'une période intercensitaire à la suivante, elles interviennent à des âges de plus en plus avancés. En 1968-1975, les employés ou ouvriers âgés de 23 à 29 ans en 1968 avaient plus de chance d'accéder à un emploi de cadre ou de membre des professions intermédiaires. En 1975-1982, les individus les plus promus ont entre 30 et 36 ans et, en 1982-1990, entre 37 et 43 ans. Cette évolution n'est que très partiellement imputable à l'augmentation de l'âge moyen d'entrée dans la vie active. Il semble donc que les générations nées pendant la seconde guerre mon- diale aient régulièrement bénéficié, de 1968 à 1990 , d'un avantage comparatif sur leurs â̂nées aussi bien que sur leurs cadettes. En toute rigueur, une comparaison définitive ne pourra être faite que lorsque les générations du début du baby boom seront arrivées à l'âge de la retraite. En 1968-1975, les très jeunes (19 ans environ en 1968) étaient plus souvent promus que les « seniors» (54 ans en 1968), en 1982-1990 l'avantage revient aux plus âgés. Ces observations convergent avec celles réalisées par Louis Chauvel par la méthode des pseudo-panels sur la base des enquêtes Formation-qualification professionnelle et des enquêtes Emploi de 1964 à 1995 (Chauvel, 1997, p. 273).

Les promotions des femmes interviennent à des âges plus avancés que pour les hommes (cf. annexe I et graphique II). Elles sont postérieures à la période où l'éducation des cnfants cn bas âgc concurrence fréquemment, pour les femmes elles-mêmes ou aux yeux de leurs employeurs, les investissements professionnels. Comme pour les hommes, elles sont, de période en période, de plus en plus tardives.

\section{Les écarts entre hommes et femmes se réduisent}

Le handicap des femmes se réduit légèrement : en 1968-1975, les chances nettes de promotion des femmes étaient inférieures de près des deux tiers à celles des hommes; en 1982-1990, elles

Encadré 2

\section{RAPPROCHEMENTS AVEC D'AUTRES SOURCES}

D'après les enquêtes Formation-qualifiquation professionnelle (FQP), 5,3\% des ouvriers et employés de 1980 étaient cadres ou membres des professions intermédiaires en 1985. Entre 1988 à 1993, le taux correspondant atteint $7,8 \%$. Ces observations corroborent celles issues de l'échantillon démographique permanent (EDP) présentées ici. Elles témoignent d'une tendance à l'accroissement des taux de mobilité professionnelle ascendante. Plus largement, on constate, à partir des enquêtes $F Q P$ comme de l'EDP, que la mobilité professionnelle s'intensifie sous toutes ses formes, qu'elle soit ascendante, descendante ou horizontale.

En revanche, l'étude de Dominique Goux centrée sur une analyse du complément Carrière et mobilité de l'enquête Emploi de 1989 (Goux, 1991) concluait à un " coup de frein sur les carrières ": les carrières sur quinze ans des personnes entrées en activité entre la fin des années 50 et le début des années 70 sont, plus souvent, ascendantes que celles des per- sonnes ayant commencé à travailler au début des années 70 (Goux, 1991 : tableaux 4 et 5).

En fait, de nombreuses différences méthodologiques réduisent les possibilités de comparaison entre les deux approches. L'étude de Goux porte sur l'ensemble de la population active. Elle s'appuie donc sur une définition extensive de la promotion : sont considérés comme des promotions, les passages d'ouvrier non qualifié à ouvrier qualifié, de membre des professions intermédiaires à cadre, etc. Les promotions sont comptabilisées à partir du premier emploi (notion absente des dispositifs du recensement et de l'EDP). Enfin, cette étude s'appuie, comme l'enquête $F Q P$, sur un questionnement rétrospectif unique et non sur un panel : les parcours d'enquêtés âgés, interrogés en 1989 sur leur premier emploi antérieur à 1960 et sur leur emploi en 1974, sont comparés à ceux d'enquêtés de quinze ans plus jeunes, décrivant leur premier emploi antérieur à 1974 et leur emploi en 1989. De plus, les périodes observées ne sont pas les mêmes. 
se rapprochent de la moitié (4). Les taux féminins bruts sont nettement plus élevés que les taux nets. Le niveau de formation plus élevé des femmes constitue la cause principale de cet écart. En 1968-1975, 28 \% des employées et ouvrières ont un niveau de diplôme supérieur au CAP-BEP contre $13 \%$ seulement pour leurs homologues masculins (en 1982-1990, respectivement $37 \%$ et $21 \%$ ). Si les femmes étaient aussi peu diplômées que les hommes, elles seraient encore bien moins souvent promues. D'un effet bien moindre, la mobilité géographique joue en sens inverse. Entre 1968 et $1975,17 \%$ des hommes ouvriers ou employés et $15 \%$ des femmes changent de département (entre 1982 et 1990, respectivement $14 \%$ et $11 \%)$ Si les femmes étaient aussi mobiles que les hommes, leur taux de promotion serait un peu plus élevé qu'il ne l'est (cf. tableau 4).

L'avantage que confère la détention d'un diplôme est tout à fait central en matière de promotion. Il ne varie guère d'une période à une autre. Cependant, l'écart entre les chances des sans diplôme et celles des diplômés, quel que soit le diplôme, se réduit légèrement (cf. annexe I et graphique I). Si les taux de promotion à niveau de formation donné étaient demeurés constants, le taux global de promotion serait passé de $9 \%$ en 1978 à $11 \%$ en 1990 , sous le seul effet de l'augmentation des niveaux de formation ; la progression effective a été presque deux fois plus importante, le taux réel atteint étant de $14 \%$. Plus en détail, $27 \%$ des ouvriers et employés de 1968, encore en emploi en 1975, n'ont pas de diplôme (n'en ont déclaré aucun), $33 \%$ ont le certificat d'études, $22 \%$ le CAP ou le BEP, $18 \%$ un diplôme plus élevé. Pour la dernière période, les chiffres correspondants sont de $18 \%, 22 \%, 32 \%$ et $28 \%$. La part des CAP et BEP passe de $25 \%$ à $38 \%$ chez les hommes et de $15 \%$ à $23 \%$ chez les femmes.

\section{Les employés de plus en plus avantagés par rapport aux ouvriers}

Les taux de promotion des employés non qualifiés (employés de commerce et personnels des services directs aux particuliers) sont voisins de ceux des ouvriers qualifiés, ceux des employés qualifiés (employés administratifs et agents de la fonction publique) se situent à un niveau un peu plus élevé, ceux des ouvriers non qualifiés sont nettement inférieurs. De 19681975 à 1982-1990, l'avantage des employés sur les ouvriers s'accentue.

Pour les hommes ouvriers, les perspectives de promotion au niveau des cadres ou des membres des professions intermédiaires sont plus grandes pour les chauffeurs et les ouvriers non qualifiés de type artisanal que pour les ouvriers non qualifiés de type industriel et les ouvriers qualifiés de type artisanal. Viennent ensuite, les ouvriers qualifiés du transport et de la manutention et enfin, les ouvriers qualifiés de type industriel. Ces derniers accèdent assez souvent à une position d'agent de maîtrise notamment (cf. annexe II). Ce classement est stable de 1968-1975 à 1982-1990.

Niveau de diplôme et catégorie socioprofessionnelle sont fortement liés. Il est possible que la légère diminution de l'effet du diplôme sur les promotions soit compensée par l'augmentation des effets de la position socioprofessionnelle. L'influence globale des deux variables demeurerait à peu près la même, l'équilibre entre elles se modifierait légèrement, l'expérience professionnelle étant valorisée au détriment des titres scolaires.

4. Le coefficient qui mesure le handicap net des femmes prend les valeurs - 1,031 puis - 0,888 et enfin - 0,814 (cf. tableau 3).

\section{Tableau 4}

\section{Effet net du genre sur le taux de promotion}

\begin{tabular}{|l|l|c|c|c|}
\hline & & $1968-1975$ & $1975-1982$ & $1982-1990$ \\
\hline $\begin{array}{l}\text { Taux de promotion } \\
\text { (en \%) }\end{array}$ & masculin observé & 10,4 & 11,6 & 15,0 \\
& féminin observé & 6,9 & 7,6 & 12,3 \\
& féminin calculé (1) & 4,0 & 5,1 & 7,3 \\
\hline \multirow{2}{*}{ Indice } & masculin observé & 100 & 100 & 86 \\
& féminin observé & 66 & 44 & 49 \\
\hline
\end{tabular}

1. Les taux calculés s'obtiennent à partir des coefficients $\beta_{i}(-1,03,-0,89$ et $-0,81)$ figurant à la ligne "Sexe féminin " du tableau 3 .

Lecture : $p_{i}=1 /\left[1+e^{(-\alpha-\beta i)}\right]$. Pour 1968-1975, $p=4,0=100 /\left[1+e^{[-\log (10,4 /(100-10,4))-(-1,031)]}\right]$.

Source : Échantillon démographique permanent, Insee. 
Tableau 3

Promotion comme cadre ou membre des professions intermédiaires Le devenir des ouvriers et employés au terme de trois périodes de sept ou huit ans

\begin{tabular}{|c|c|c|c|c|c|c|c|c|c|}
\hline & \multicolumn{8}{|c|}{ Promus en fin de période } \\
\hline & & $1968-1975$ & $1975-1982$ & $1982-1990$ & 3 périodes & $1968-1975$ & 1975-1982 & $1982-1990$ & 3 périodes \\
\hline \multicolumn{2}{|c|}{ Situation de référence } & $-3,48$ & $-3,64$ & $-3,39$ & $-3,60$ & 3,0 & 2,6 & 3,3 & 2,7 \\
\hline & & \multicolumn{4}{|c|}{ Coefficients Logits } & \multicolumn{4}{|c|}{ Écart à la situation de référence (en \%) } \\
\hline \multirow[t]{6}{*}{ Âge } & 16 à 22 ans & $-0,33$ & $-0,47$ & $-0,27$ & $-0,33$ & $-0,8$ & $-0,9$ & $-0,8$ & $-0,7$ \\
\hline & 23 à 29 ans & Réf. & Réf. & Réf. & Réf. & - & - & - & - \\
\hline & 30 à 36 ans & $-0,08$ & 0,13 & 0,24 & 0,12 & $-0,2$ & 0,4 & 0,9 & 0,3 \\
\hline & 37 à 43 ans & $-0,22$ & n.s. & 0,26 & 0,05 & $-0,6$ & n.s. & 0,9 & 0,1 \\
\hline & 44 à 50 ans & $-0,55$ & n.s. & 0,11 & $-0,14$ & $-1,3$ & n.s. & 0,4 & $-0,3$ \\
\hline & 51 à 57 ans & $-0,81$ & $-0,27$ & $-0,04$ & $-0,36$ & $-1,6$ & $-0,6$ & $-0,1$ & $-0,8$ \\
\hline \multirow[t]{3}{*}{ Période } & $1968-1975$ & III & III & "I & $-0,06$ & III & III & III & $-0,2$ \\
\hline & 1975-1982 & III & III & III & Réf. & III & III & III & - \\
\hline & $1982-1990$ & III & III & III & 0,26 & III & III & III & 0,8 \\
\hline \multirow[t]{4}{*}{ Diplôme } & $\begin{array}{l}\text { Sans diplôme, } \\
\text { non déclaré }\end{array}$ & Réf. & Réf. & Réf. & Réf. & - & - & - & - \\
\hline & CEP & 0,98 & 0,84 & 0,41 & 0,74 & 4,6 & 3,2 & 1,6 & 2,8 \\
\hline & $\begin{array}{l}\text { CAP, BEP } \\
\text { ou équivalent }\end{array}$ & 1,25 & 1,23 & 0,92 & 1,13 & 6,7 & 5,7 & 4,5 & 5,2 \\
\hline & $\begin{array}{l}\text { Supérieur } \\
\text { au CAP-BEP }\end{array}$ & 2,29 & 2,21 & 2,00 & 2,14 & 20,4 & 16,8 & 16,7 & 16,3 \\
\hline \multirow{2}{*}{$\begin{array}{l}\text { Mobilité } \\
\text { géographique }\end{array}$} & Même département & Réf. & Réf. & Réf. & Réf. & - & - & - & - \\
\hline & $\begin{array}{l}\text { Dép. différents } \\
\text { aux } 2 \text { recensements }\end{array}$ & 0,36 & 0,34 & 0,48 & 0,39 & 1,2 & 1,0 & 1,9 & 1,2 \\
\hline \multirow{2}{*}{$\begin{array}{l}\text { Secteur } \\
\text { d'activité }\end{array}$} & Industrie & Réf. & Réf. & Réf. & Réf. & - & - & - & - \\
\hline & Tertiaire & $-0,11$ & $-0,16$ & $-0,24$ & $-0,16$ & $-0,3$ & $-0,4$ & $-0,7$ & $-0,4$ \\
\hline \multirow[t]{3}{*}{ Nationalité } & Français de naissance & Réf. & Réf. & Réf. & Réf. & - & - & - & - \\
\hline & $\begin{array}{l}\text { Français par } \\
\text { acquisition }\end{array}$ & n.s. & n.s. & n.s. & n.s. & n.s. & n.s. & n.s. & n.s. \\
\hline & Étranger & $-0,63$ & $-0,55$ & $-0,71$ & $-0,62$ & $-1,4$ & $-1,1$ & $-1,6$ & $-1,2$ \\
\hline \multirow{4}{*}{$\begin{array}{l}\text { Catégories } \\
\text { socio- } \\
\text { professionelles }\end{array}$} & Employé qualifié & 0,84 & 0,87 & 1,13 & 0,96 & 3,7 & 3,4 & 6,1 & 4,0 \\
\hline & Employé non qualifié & 0,61 & 0,66 & 0,75 & 0,66 & 2,4 & 2,3 & 3,4 & 2,4 \\
\hline & Ouvrier qualifié & 0,54 & 0,76 & 0,59 & 0,64 & 2,0 & 2,8 & 2,5 & 2,3 \\
\hline & Ouvrier non qualifié & Réf. & Réf. & Réf. & Réf. & - & - & - & - \\
\hline \multirow[t]{2}{*}{ Sexe } & Masculin & Réf. & Réf. & Réf. & Réf. & $\cdot$ & - & - & - \\
\hline & Féminin & $-1,03$ & $-0,89$ & $-0,81$ & $-0,88$ & $-1,9$ & $-1,5$ & $-1,8$ & $-1,5$ \\
\hline \multirow{4}{*}{$\begin{array}{l}\text { Tranche } \\
\text { d'unité urbaine }\end{array}$} & Communes rurales & $-0,40$ & $-0,32$ & $-0,24$ & $-0,31$ & $-1,0$ & $-0,7$ & $-0,7$ & $-0,7$ \\
\hline & $\begin{array}{l}\text { De } 2000 \text { à } 99999 \\
\text { habitants }\end{array}$ & $-0,19$ & $-0,15$ & $-0,12$ & $-0,15$ & $-0,5$ & $-0,4$ & $-0,3$ & $-0,4$ \\
\hline & $\begin{array}{l}\text { De } 100000 \\
\text { à } 1999999 \mathrm{~h} .\end{array}$ & Réf. & Réf. & Réf. & Réf. & - & - & - & - \\
\hline & $\begin{array}{l}\text { Agglomération } \\
\text { parisienne }\end{array}$ & 0,12 & 0,19 & 0,43 & 0,26 & 0,4 & 0,5 & 1,7 & 0,8 \\
\hline
\end{tabular}

Lecture : pour une personne ouvrier ou employé en 1982 qui présentait les caractéristiques correspondant à la situation de référence, la probabilité pour qu'elle soit cadre ou profession intermédiaire en 1990 était de 3,3\%. Le logit de cette probabilité est de - 3,39.

Pour une personne se trouvant dans la situation de référence, à ceci près qu'elle résidait dans l'agglomération parisienne en 1982, la probabilité $p_{i}$ d'être promue en 1990 est de $5 \%$. La valeur de $5 \%$ se déduit des coefficients $\alpha$ (logit du taux de chômage estimé pour la situation de référence) et $\beta_{i}\left(\log\right.$ de l'odds ratio $\left[p_{i} /\left(1-p_{i}\right)\right] /[p /(1-p)]$ par la formule $p_{i}=1 /\left(1+e^{-\alpha-\beta i)}\right)$.

Ici, $\alpha$ vaut $-3,39$ (tableau 3, tère ligne, $3^{\circ}$ colonne) et $\beta_{i}+0,43$ (dernière ligne, $3^{\circ}$ colonne).

Source : Échantillon démographique permanent, Insee. 


\section{Mobilité géographique et mobilité professionnelle vont souvent de pair}

Les individus qui changent de département ont de meilleures chances de promotion que les sédentaires. Bien entendu, les deux types de mouvements sont interdépendants : on peut changer de département à l'occasion d'une promotion comme on peut rencontrer de nouvelles occasions de promotion, parce qu'on a changé de cadre de vie. Cette association se retrouve pour les femmes comme pour les hommes (cf. annexe I), mais les femmes plus mobiles sont exposées à un surcroît massif de risque de chômage : on peut penser que cet écart concerne surtout les femmes vivant en couple.

Contrairement aux tendances habituellement repérées dans le cadre des analyses portant sur les évolutions de salaires (voir, par exemple, Beret, 1992, p. 6 : « l'avantage salarial du marché interne d'entreprises par rapport au marché externe » constitue un « fait empirique incontestable "), les " marchés internes » ne semblent pas offrir de meilleures perspectives de promotion que les « marchés externes»: les chances de promotion sont à peu près les mêmes pour ceux qui sont fidèles à leur établissement que pour ceux qui changent d'établissement sans changer de secteur (cf. annexe II). La mobilité géographique sans changement d'entreprise est peut-être plus favorable que celle qui est associée à un changement de groupe ou d'entreprise. Cependant, elle est impossible à chiffrer ici, seuls les changements d'établissement étant renseignés dans l'EDP.

\section{Ouvriers et employés chez EDF-GDF : une promotion plus facile}

Le secteur industriel offre un peu plus de chances de promotion que le secteur tertiaire (cf. tableau 3). Cet écart résulte, en grande partie, de la faible promotion des personnels des services directs aux particuliers. Pour les hommes, le secteur de la production et distribution d'énergie électrique (c'est-à-dire, essentiellement, EDF-GDF) se distingue par la fréquence des promotions et cet avantage se renforce encore légèrement en 1982-1990 (cf. annexe II). On relève une dégradation très nette dans le secteur de la construction automobile, qui offrait des chances de promotion supérieures à la moyenne en 1968-1975 et qui, à l'inverse, se situe significativement au-dessous de celle-ci en 1982-1990. La Poste et les assurances semblent offrir de bonnes perspectives de promotion pour les femmes, à l'inverse du secteur de la santé et des organismes financiers.

\section{Moitié moins de promotions pour les étrangers}

L.-A. Vallet a montré qu'au collège, les élèves étrangers ou issus de l'immigration réussissent mieux, «toutes choses égales d'ailleurs », que les autres enfants (Vallet et Caille, 1995). Il en va tout autrement dans le registre des carrières professionnelles. Quelle que soit la période considérée, les chances nettes d'accès à l'encadrement ou au salariat très qualifié sont presque moitié moindres pour un étranger que pour un Français de naissance. Les Français par acquisition voient leur position, auparavant très proche de celle des Français de naissance, se dégrader légèrement en 1982-1990 (l'écart avec les Français de naissance n'est pas significatif pour l'ensemble de la population, mais il l'est pour les hommes ; cf. tableau 3 et annexes I et II). En 1990, il ne s'agit pas des mêmes personnes qu'en 1960, ni des mêmes nationalités d'origine : la part des pays de l'Europe du sud diminue, celle du Maghreb s'accroît.

Dans les années 1968-1975, les employés et ouvriers de l'agglomération parisienne (localisation observée en début de période) étaient avantagés en termes de perspectives de promotion comme cadres ou membres des professions intermédiaires. Dans les années 1982-1990, leur position est encore plus favorable. Cette tendance à un accroissement de la polarisation du territoire au profit de la capitale concerne également l'évolution de la mise à son compte et celle des risques de chômage (voir supra). Elle s'inscrit dans un tableau d'ensemble qui englobe, par ailleurs, l'évolution de la distribution spatiale des catégories socioprofessionnelles (Chenu et Tabard, 1993) et celle des revenus des ménages : de 1989 à 1994 , le taux annuel moyen d'accroissement du niveau de vie des ménages est de $2 \%$ en Île-de-France et de $1,5 \%$ pour la France entière (Insee, 1997).

\section{Le mariage favorise les carrières des hommes et entrave celle des femmes}

Les hommes célibataires sont moins souvent promus que ceux qui sont mariés. La relation est inverse pour les femmes ; toutefois, les écarts sont moindres (cf. annexes I et II). Ces observations confirment de nombreuses analyses antérieures (de Singly, 1982 ; Vallet, 1995). 
Graphique I

Chances de promotion comme cadre ou membre des professions libérales

Échelle logit

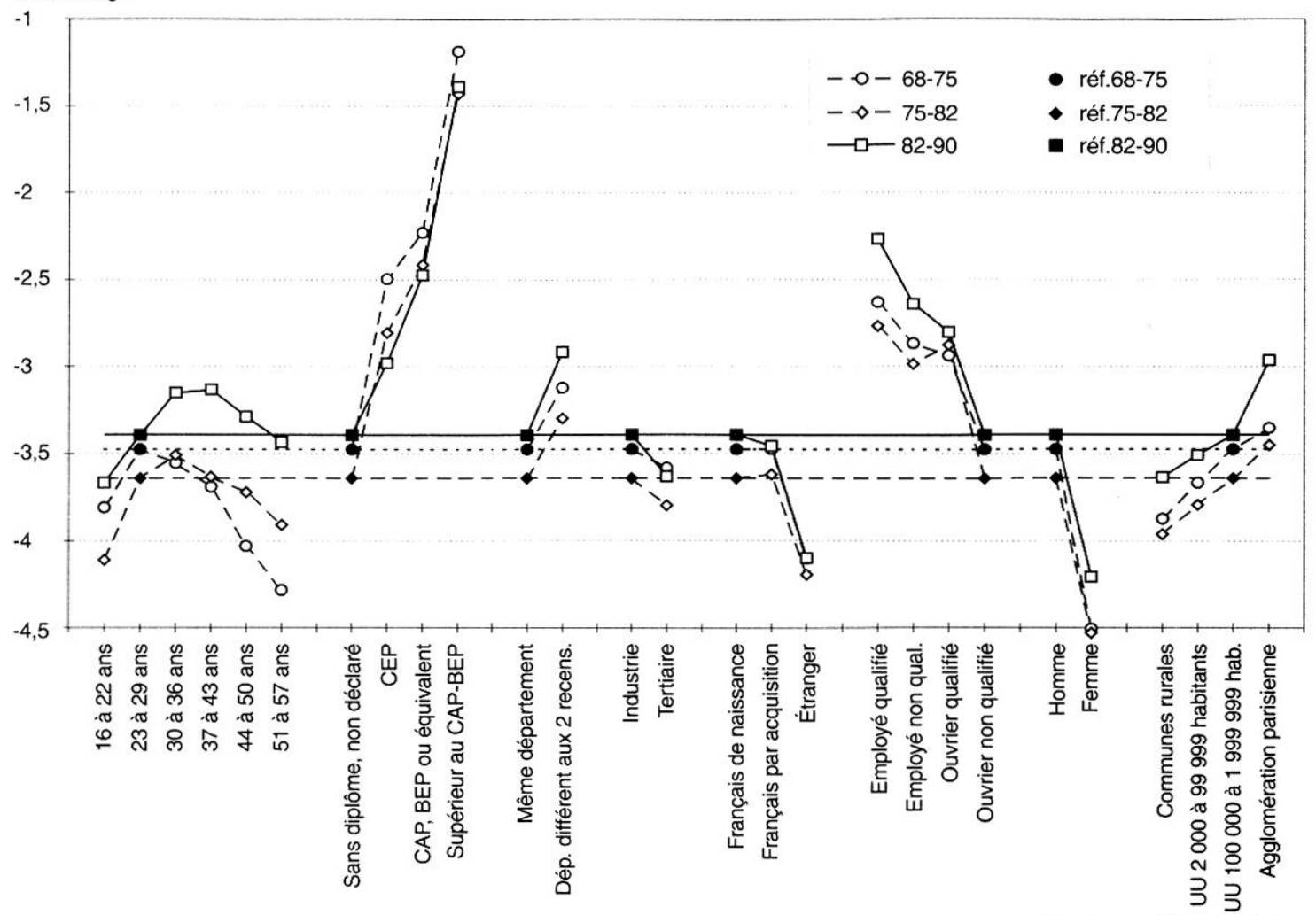

Situation en début de période

Lecture : pour une personne qui en 1982 occupait un emploi d'ouvrier ou d'employé et se trouvait dans la situation de référence, le logit de la probabilité pour qu'elle soit cadre ou membre des professions intermédiaires en 1990 est de - 3,4 environ; la position des carrés noirs, d'ordonnée - 3,4, permet de caractériser la situation de référence : 23 à 29 ans, sans diplôme, etc. Un logit de - 3,4 correspond à une probabilité de 3,3\% (tableau 3). Pour une personne s'écartant de la situation de référence par un diplôme de niveau supérieur au $C A P-B E P$, le logit de la probabilité d'accès à un emploi de cadre ou à une profession intermédiaire est de - 1,4 environ (c'est-à-dire que cette probabilité est de $20 \%$ ).

Source : Échantillon démographique permanent, Insee.

\section{Graphique II}

\section{Effet net de l'âge sur les chance de promotion comme cadre ou membre des professions libérales}

\section{A- Hommes}

Logit du taux de promotion

$-3$

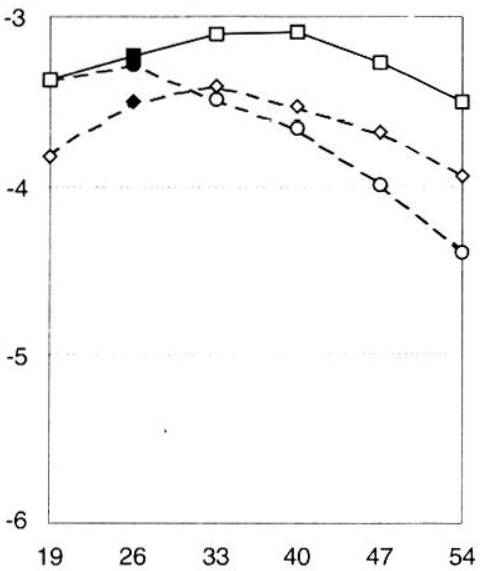

\section{B - Femmes}

Logit du taux de promotion

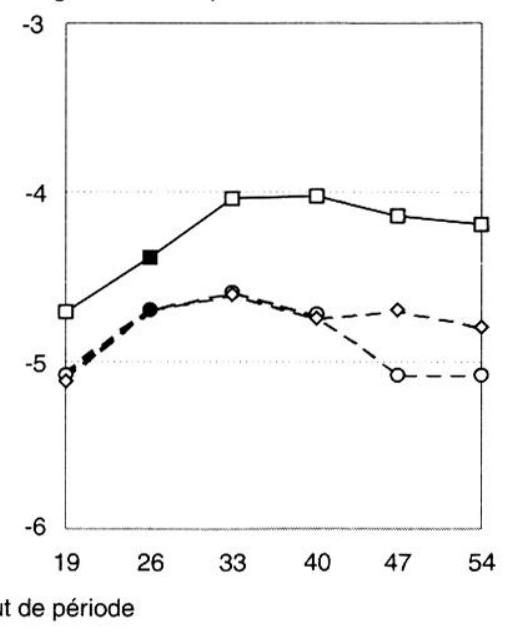

- - - 1968-1975

$\sim \sim-1975-1982$ $1982-1990$

Symboles noirs : situation de référence.

Source : Échantillon démographique permanent, Insee. 
Du fait du développement de la cohabitation hors mariage, ces effets inversés sont cependant moins accentués sur la période 1982-1990 qu'auparavant. Les hommes veufs ou divorcés sont, eux aussi, moins souvent promus que les mariés. Pour les femmes veuves ou divorcées, l'avantage qu'elles avaient sur leurs homologues mariées disparaît après 1975 .

L'étude des rapports entre carrières et situation de famille nécessiterait la prise en compte d'autres informations (sur la vie en couple, le nombre et l'âge des enfants), absentes du fichier de l'EDP.

\section{Les perspectives de mise à son compte sont stables...}

$\mathrm{L}$ es taux nets de mise à son compte, pour les trois périodes intercensitaires, sont très proches les uns des autres (cf. tableau 5 et graphique III) : l'établissement des ouvriers et employés comme patrons résulte de conditions qui ont peu évolué au fil des dernières décennies. Une baisse de ces taux, faible mais sensible, intervient entre les années 1975-1982 et la période 1982-1990. Elle est d'autant plus significative que cette période dure une année de plus que les précédentes.

Les « chances » d'accès au statut d'artisan, commerçant ou chef d'entreprise varient massivement en fonction de l'âge. En 1968-1975 et 1975-1982, elles décroissent fortement et régulièrement au-delà de trente ans ; en 1982-1990, le décrochage est plus tardif et intervient à partir de 37 ans. Le mot «chance » est pris, ici, au sens probabiliste du terme. En effet, le passage au statut d'indépendant ou d'employeur signi- fie le plus souvent, mais pas toujours, une amélioration de la situation des ouvriers et employés concernés (Laulhé, 1988). Toutefois, les observations issues du fichier de l'EDP et des enquêtes Formation-qualification professionnelle (non détaillées ici) montrent que les taux de passage d'une position de patron (hors agriculture) à une position de salarié peu qualifié, ouvrier ou employé, sont plus élevés vers 1990 que dans les périodes antérieures.

Comme la promotion au sein du monde salarié, la mise à son compte est plus aisée pour les hommes que pour les femmes. L'écart entre les taux nets masculins et féminins est moins marqué que pour les promotions et reste à peu près stable. Si les femmes présentaient les mêmes caractéristiques que les hommes (en matière de diplômes, de mobilité, etc.), leurs taux de mise à leur compte seraient alors, sur les deux dernières périodes, un peu plus forts que les taux effectivement observés (cf. tableau 6).

Pour les femmes, les probabilités de mise à son compte dépendent moins de l'âge que pour les hommes, notamment au cours de la période 1982-1990 (cf. graphique IV). Comme pour l'accès des hommes aux positions de cadre ou de profession intermédiaire, on observe, de 1968-1975 à 1982-1990, une nette élévation de l'âge auquel le changement de statut est le plus fréquent. Les femmes nées de 1939 à 1945 bénéficient, à chaque période, d'un avantage sur les autres générations.

Le rôle du diplôme dans l'accès au statut d'indépendant ou d'employeur est important, mais moins écrasant que pour les promotions de cadre ou membre des professions intermédiaires. Le processus de dévalorisation des diplômes a la même ampleur mais est plus régulier (cf. graphiques I et III).

\section{Tableau 6 \\ Effet net du genre sur le taux de mise à son compte}

\begin{tabular}{|l|l|c|c|c|}
\hline & & $1968-1975$ & $1975-1982$ & $1982-1990$ \\
\hline $\begin{array}{l}\text { Taux de mise à son } \\
\text { compte (en \%) }\end{array}$ & masculin observé & 4,0 & 4,4 & 4,5 \\
& féminin observé & 2,1 & 1,6 & 1,8 \\
& féminin calculé & 2,1 & 2,1 & 2,3 \\
\hline \multirow{2}{*}{ Indice } & masculin observé & 100 & 100 & 100 \\
& féminin observé & 53 & 36 & 40 \\
& féminin calculé & 53 & 48 & 51 \\
\hline
\end{tabular}

Source : Échantillon démographique permanent, Insee. 
Tableau 5

Mise à son compte

Devenir des ouvriers et employés au terme de trois périodes de sept ou huit ans

\begin{tabular}{|c|c|c|c|c|c|c|c|c|c|}
\hline & & \multicolumn{8}{|c|}{ Indépendant ou employeur en fin de période } \\
\hline & & 1968-1975 & 1975-1982 & 1982-1990 & 3 périodes & $1968-1975$ & $1975-1982$ & 1982-1990 & 3 périodes \\
\hline \multicolumn{2}{|c|}{ Situation de référence } & $-3,71$ & $-3,76$ & $-3,82$ & $-3,80$ & 2,4 & 2,3 & 2,1 & 2,2 \\
\hline & & \multicolumn{4}{|c|}{ Coefficients Logit } & \multicolumn{4}{|c|}{ Écart à la situation de référence (en \%) } \\
\hline \multirow[t]{6}{*}{ Âge } & 16 à 22 ans & $-0,52$ & $-0,38$ & $-0,19$ & $-0,35$ & $-0,9$ & $-0,7$ & $-0,4$ & $-0,6$ \\
\hline & 23 à 29 ans & Réf. & Réf. & Réf. & Réf. & - & - & - & - \\
\hline & 30 à 36 ans & $-0,27$ & $-0,14$ & 0,05 & n.s. & $-0,6$ & $-0,3$ & 0,1 & n.s. \\
\hline & 37 à 43 ans & $-0,65$ & $-0,55$ & $-0,23$ & $-0,48$ & $-1,1$ & $-1,0$ & $-0,4$ & $-0,8$ \\
\hline & 44 à 50 ans & $-1,09$ & $-0,98$ & $-0,68$ & $-0,91$ & $-1,6$ & $-1,4$ & $-1,0$ & $-1,3$ \\
\hline & 51 à 57 ans & $-1,20$ & $-1,19$ & $-0,58$ & $-1,05$ & $-1,7$ & $-1,6$ & $-0,9$ & $-1,4$ \\
\hline \multirow[t]{3}{*}{ Période } & $1968-1975$ & III & III & III & n.s. & III & III & III & n.s. \\
\hline & 1975-1982 & III & III & III & Réf. & III & III & III & - \\
\hline & $1982-1990$ & III & III & III & $-0,07$ & III & III & III & $-0,1$ \\
\hline \multirow[t]{4}{*}{ Diplôme } & $\begin{array}{l}\text { Sans diplôme, } \\
\text { non déclaré }\end{array}$ & Réf. & Réf. & Réf. & Réf. & - & $\cdot$ & - & - \\
\hline & CEP & 0,50 & 0,50 & 0,26 & 0,45 & 1,5 & 1,4 & 0,6 & 1,2 \\
\hline & $\begin{array}{l}\text { CAP, BEP } \\
\text { ou équivalent }\end{array}$ & 0,83 & 0,82 & 0,68 & 0,80 & 2,9 & 2,7 & 2,0 & 2,5 \\
\hline & $\begin{array}{l}\text { Supérieur } \\
\text { au CAP-BEP }\end{array}$ & 1,09 & 1,00 & 0,97 & 1,03 & 4,4 & 3,7 & 3,3 & 3,7 \\
\hline \multirow{2}{*}{$\begin{array}{l}\text { Mobilité } \\
\text { géographique }\end{array}$} & Même département & Réf. & Réf. & Réf. & Réf. & - & - & - & - \\
\hline & $\begin{array}{l}\text { Dép. différents } \\
\text { aux } 2 \text { recensements }\end{array}$ & 0,47 & 0,58 & 0,61 & 0,55 & 1,4 & 1,7 & 1,8 & 1,5 \\
\hline \multirow{2}{*}{$\begin{array}{l}\text { Secteur } \\
\text { d'activité }\end{array}$} & Industrie & Réf. & Réf. & Réf. & Réf. & - & - & $\cdot$ & $\cdot$ \\
\hline & Tertiaire & 0,27 & 0,12 & 0,03 & 0,12 & 0,7 & 0,3 & 0,1 & 0,3 \\
\hline \multirow[t]{3}{*}{ Nationalité } & $\begin{array}{l}\text { Français de } \\
\text { naissance }\end{array}$ & Réf. & Réf. & Réf. & Réf. & - & - & $\cdot$ & $\cdot$ \\
\hline & $\begin{array}{l}\text { Français par } \\
\text { acquisition }\end{array}$ & n.s. & 0,29 & n.s. & n.s. & n.s. & 0,8 & n.s. & n.s. \\
\hline & Étranger & n.s. & n.s. & 0,57 & 0,22 & n.s. & n.s. & 1,6 & 0,5 \\
\hline \multirow{4}{*}{$\begin{array}{l}\text { Catégories } \\
\text { socio- } \\
\text { professionelles }\end{array}$} & Employé qualifié & $-1,04$ & $-1,27$ & $-1,12$ & $-1,14$ & $-1,5$ & $-1,6$ & $-1,4$ & $-1,5$ \\
\hline & Employé non qualifié & 1,30 & 1,00 & 1,00 & 1,12 & 5,9 & 3,7 & 3,5 & 4,2 \\
\hline & Ouvrier qualifié & 0,38 & 0,38 & 0,34 & 0,38 & 1,1 & 1,0 & 0,8 & 1,0 \\
\hline & Ouvrier non qualifié & Réf. & Réf. & Réf. & Réf. & - & $\cdot$ & - & - \\
\hline \multirow[t]{2}{*}{ Sexe } & Masculin & Réf. & Réf. & Réf. & Réf. & - & - & $\cdot$ & - \\
\hline & Féminin & $-0,67$ & $-0,78$ & $-0,69$ & $-0,72$ & $-1,2$ & $-1,2$ & $-1,1$ & $-1,1$ \\
\hline \multirow{4}{*}{$\begin{array}{l}\text { Tranche } \\
\text { d'unité urbaine }\end{array}$} & Communes rurales & 0,31 & 0,29 & 0,17 & 0,27 & 0,9 & 0,7 & 0,4 & 0,6 \\
\hline & $\begin{array}{l}\text { UU } 2000 \\
\text { à } 99999 \text { habitants }\end{array}$ & n.s. & 0,103 & 0,048 & 0,08 & n.s. & 0,2 & 0,1 & 0,2 \\
\hline & $\begin{array}{l}\text { UU } 100000 \\
\text { à } 1999999 \mathrm{~h} .\end{array}$ & Réf. & Réf. & Réf. & Réf. & - & - & - & - \\
\hline & $\begin{array}{l}\text { Agglomération } \\
\text { parisienne }\end{array}$ & 0,20 & $-0,15$ & $-0,11$ & $-0,15$ & $-0,4$ & $-0,3$ & $-0,2$ & $-0,3$ \\
\hline
\end{tabular}

Source : Échantillon démographique permanent, Insee. 


\section{... et plus favorables pour les employés non qualifiés}

La mise à son compte est plus fréquente pour les employés non qualifiés (employés de commerce, personnels des services directs aux particuliers) : elle prend la forme de la création ou de la transmission familiale d'un petit commerce, d'un café, d'un restaurant. Inversement, elle est rarissime parmi les employés qualifiés, catégorie qui regroupe de nombreux fonctionnaires et salariés administratifs relevant souvent de grandes firmes. Conformément aux attentes, elle est très fréquente parmi les ouvriers de type artisanal, notamment les plus qualifiés, et pour les chauffeurs. Dans l'ensemble, la probabilité nette, pour les ouvriers qualifiés de type artisanal, de se mettre à son compte ou de devenir cadre ou membre des professions intermédiaires est à peu près la même que celle des ouvriers qualifiés de type industriel.

La mobilité géographique favorise (ou est favorisée par) la mise à son compte. Devenir artisan ou commerçant implique, en général, un changement d'établissement (cf. annexe II), mais le changement de secteur d'activité semble sans effet.

Le secteur tertiaire offrait en 1968-1975 des chances de mise à son compte plus fréquentes que celles de l'industrie. Cet écart a pratiquement disparu en 1982-1990. Quatre secteurs se distinguent par de nombreux passages au statut d'indépendant ou d'employeur : la boulangerie-pâtisserie, puis le commerce de détail et les cafés-hôtels-restaurants, le bâtiment et, enfin, les garages et commerces d'automobiles. Les taux par secteur sont d'une assez grande stabilité. L'histoire du monde artisanal paraît être moins mouvementée que celle de l'industrie.

Jusqu'en 1982, la situation des étrangers était très voisine de celle des Français de naissance. Au cours des années 1982-1990, les étrangers sont plus nombreux que les Français (de naissance ou par acquisition) à devenir artisan, commerçant ou chef d'entreprise.

La mise à son compte est plus fréquente à la campagne qu'en ville, dans les petites unités urbaines que dans les grandes : la part plus importante de petites entreprises dans les petites agglomérations explique cette tendance. Plus intércssantc cst l'atténuation des spécificités du monde rural : les chances nettes de mise à son compte ont fortement diminué à la campagne et dans les petites villes, alors qu'elles restaient stables dans la capitale.
À l'inverse de ce que l'on observe pour la promotion à un emploi salarié hautement qualifié, les employées et ouvrières célibataires sont moins nombreuses que les femmes mariées à se mettre à leur compte (cf. annexes I et II). En effet, une entreprise artisanale ou commerciale est souvent une affaire de famille, gérée sous la formule d'un «mariage-association » et relativement peu compatible avec le célibat, qu'il soit féminin ou masculin. Cependant, en termes de cumul de promotion et de mise à son compte, les femmes célibataires gardent un petit avantage sur les femmes mariées.

\section{Les risques de chômage des ouvriers et employés triplent entre 1975 et 1982}

Certes, des observations instantanées, et non longitudinales, se prêtent à l'étude du chômage. Cependant, l'intérêt de la prise en compte du chômage éventuel au terme d'une période de sept ou huit années est double. D'une part, la comparabilité avec les autres destinées analysées ici est ainsi assurée. D'autre part, les informations sur la situation d'emploi au recensement antérieur, collectées à un moment où la personne n'était pas au chômage, sont plus sûres et plus complètes que celles, rétrospectives, qu'un chômeur peut fournir à propos du dernier emploi qu'il a occupé (cf. tableau 7).

Les variations de l'incidence du chômage en fonction de l'âge suivent une courbe en $J$ (cf. graphique V). Pour les périodes 1968-1975 et 1975-1982, c'est entre 37 et 43 ans que l'on a le moins de «chances » d'être mis au chômage. Entre 1982 et 1990, la tranche d'âge correspondante est entre 30 et 36 ans. À toutes les périodes, les plus âgés sont un peu plus exposés que les plus jeunes. De 1968-1975 à 1975-1982, la montée du chômage s'opère sans que le lien avec l'âge se modifie (cf. graphique $\mathrm{V}$ où la courbe de 1982 semble résulter d'une simple translation vers le haut de celle de 1975). En 1990, la montée se poursuit, mais la nouvelle translation ne concerne que les âges intermédiaires : le risque de chômage des 16-22 ans et 51-57 ans reste à peu près au niveau de 1982 . On retrouve, probablement, l'effet de mesures spécifiques (stages, préretraites, etc.) adoptées ou renforcées dans les années 80 , qui, provisoirement ou durablement, soustraient du chômage des personnes appartenant à des tranches 
Graphique III

\section{Chances de mise à son compte}

Échelle logit

$-2$

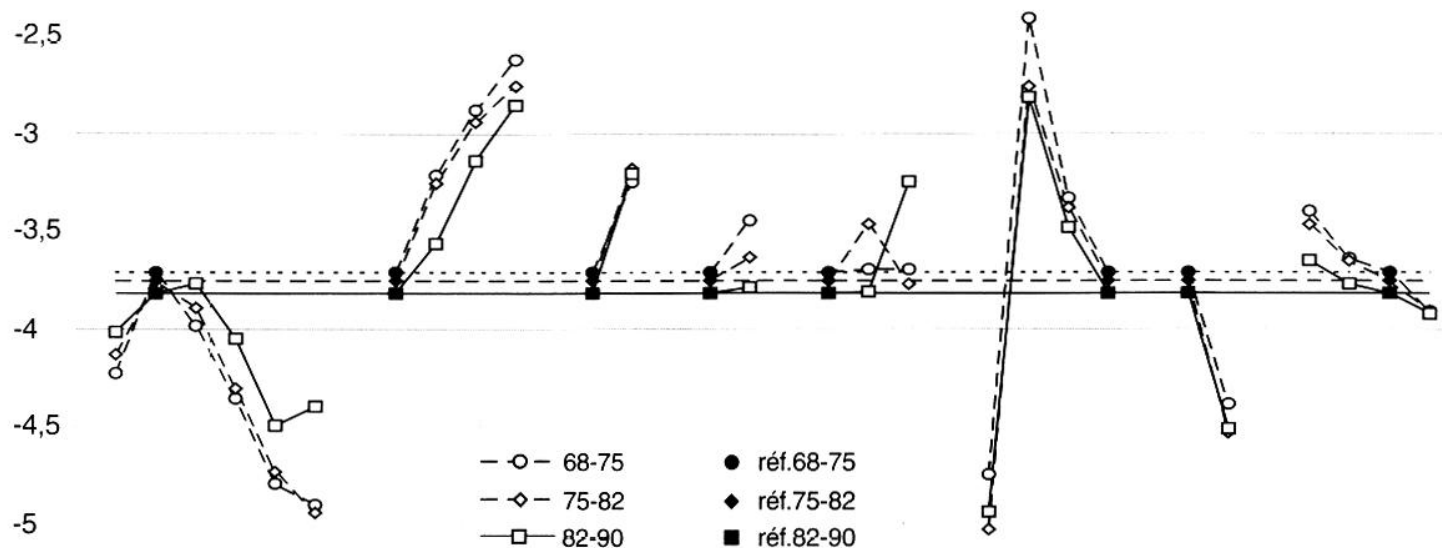

$-5,5$

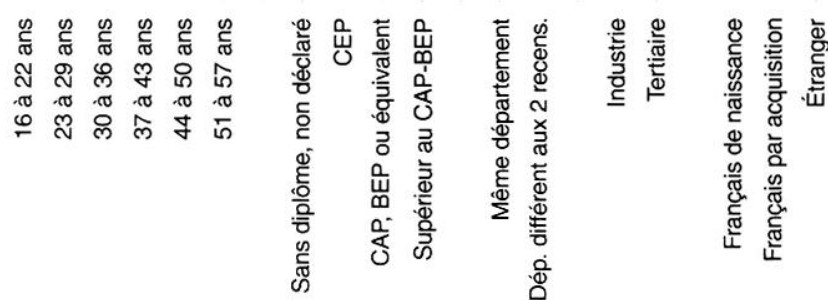

ส กิ

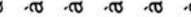

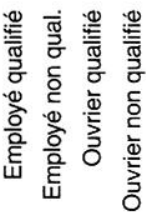

है छํำ

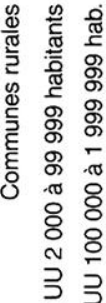

Situation en début de période

Source : Échantillon démographique permanent, Insee.

Graphique IV

Effet de l'âge sur les chances de mise à son compte

\section{A- Hommes}

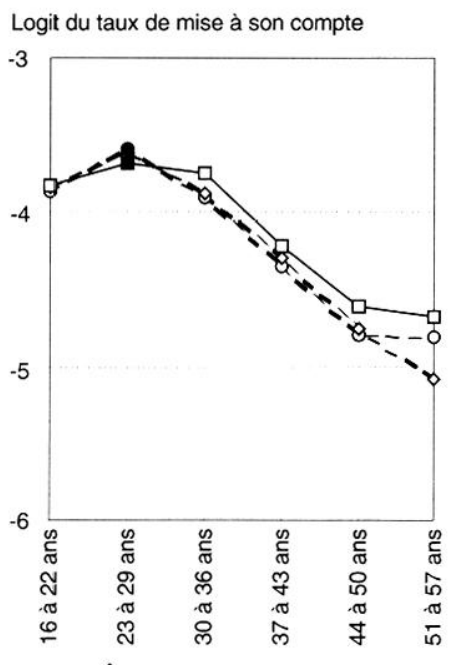

Âge en début de période

$-\infty-1968-1975$

\section{B - Femmes}

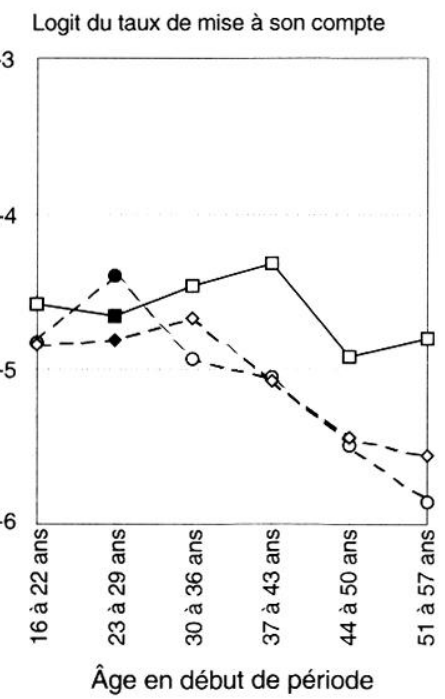

$1982-1990$ 
Graphique V

\section{Risques de chômage}

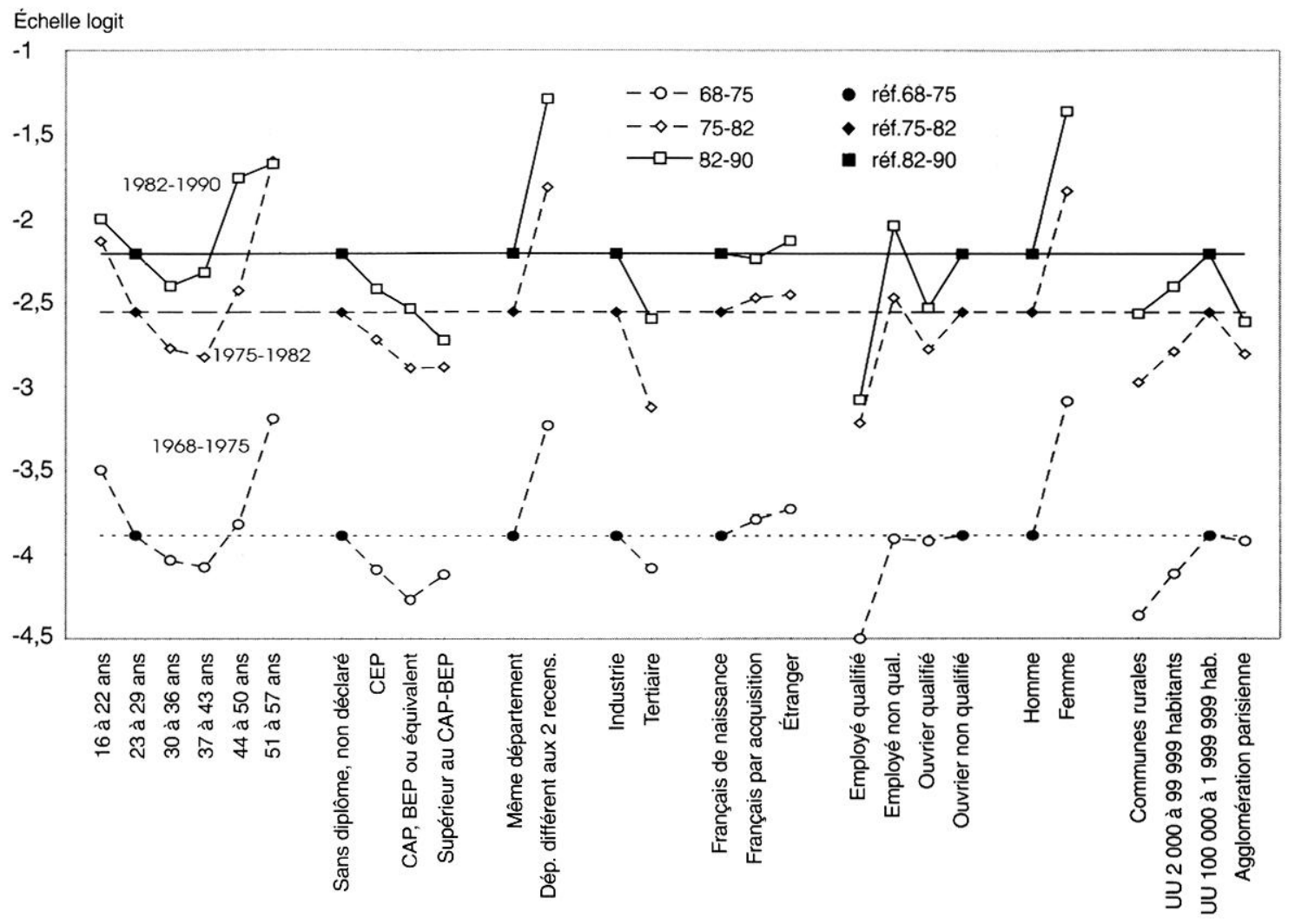

Situation en début de période

Source : Échantillon démographique permanent, Insee.

\section{Graphique VI}

\section{Effet de l'âge sur les risques de chômage}

\section{A-Hommes}

Logit du taux de chômage

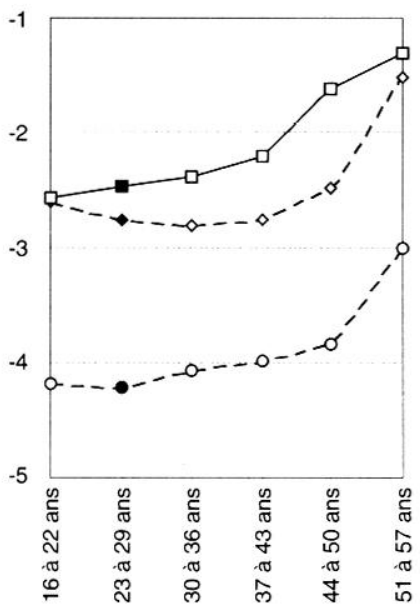

Âge en début de période

- - - 1968-1975

Symboles noirs : situation de référence.

Source : Échantillon démographique permanent, Insee.

\section{B - Femmes}

Logit du taux de chômage

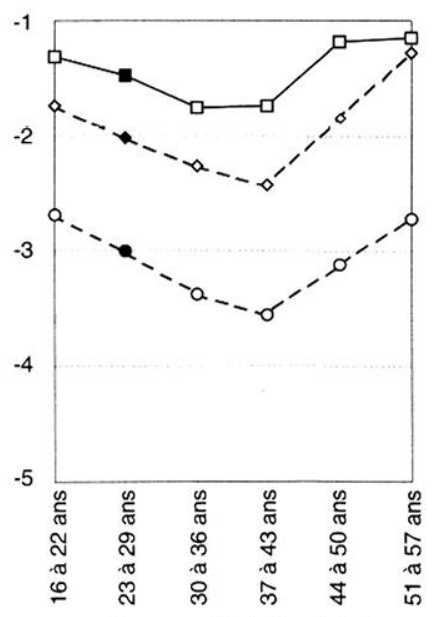

Àge en début de période

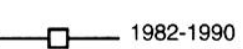


Tableau 7

Risques de chômage

Devenir des ouvriers et employés au terme de trois périodes de sept ou huit ans

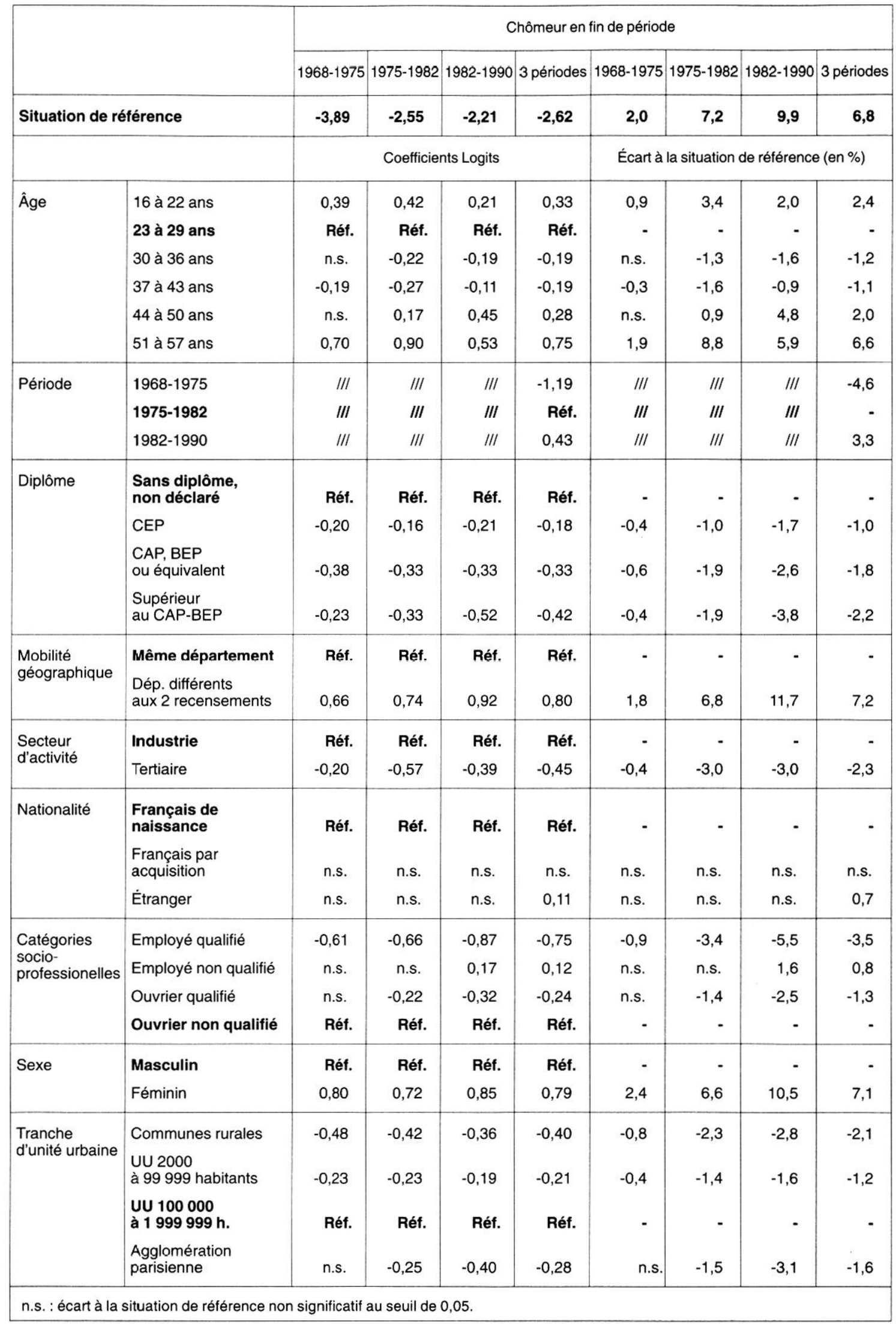

Source : Échantillon démographique permanent, Insee. 
d'âge particulièrement exposées au sous-emploi. Dans l'ensemble, les risques nets de chômage triplent de 1975 à 1982 et progressent de $40 \%$ environ de 1982 à 1990.

Le risque de chômage féminin est deux fois plus élevé que pour les hommes. Cette surexposition demeure constante au long des 22 années étudiées. Elle est plus faible en termes de taux bruts qu'en termes nets (cf. tableau 8) : si les femmes étaient aussi peu diplômées que les hommes, si elles relevaient du secteur industriel aussi souvent que les hommes, etc., elles souffriraient encore davantage du sous-emploi. La surexposition féminine au chômage concerne surtout les jeunes et les personnes d'âge moyen : les plus de cinquante ans sont en situation défavorable, qu'ils soient hommes ou femmes (cf. annexe I et graphique VI). Le profil des risques de chômage masculin, en J, évolue vers une croissance presque monotone en 1982-1990 ; celui des taux féminins est en V, le risque étant minimum vers quarante ans.

La vulnérabilité face au chômage des hommes célibataires est particulièrement forte et, plus encore, celle des veufs ou divorcés. Les femmes célibataires, depuis les années 1975-1982, sont plus exposées au sous-emploi que celles qui sont mariées, alors que la situation des veuves ou divorcées, qui s'écartait peu de celles des mariées, se dégrade en 1982-1990.

\section{Le diplôme : une protection contre le chômage de plus en plus efficace}

En termes de risque de chômage, le bénéfice d'un niveau de diplôme élevé et le caractère pénalisant d'une absence de diplôme ou de la détention d'un simple certificat d'études primaires s'affirment, pour les hommes, à partir des années 1975-1982. Les femmes sont, de plus en plus, protégées par les diplômes supérieurs au CAP-BEP; en revanche, au-delà de 1975, la détention d'un CAP ou d'un BEP ne procure plus de protection significative par comparaison avec les niveaux de formation inférieurs. Ces diplômes professionnels de niveau $\mathrm{V}$ ont conservé, pour les hommes, une certaine valeur perdue, semble-t-il, pour les femmes.

En matière de risque de chômage, la surexposition des ouvriers qualifiés de type artisanal s'estompe. Le rôle pénalisant d'un faible niveau de qualification tend à s'accrô̂tre. Pour les employées, le bénéfice de l'appartenance à la Fonction publique d'une part, le handicap des personnels de service et surtout des employées de commerce (dès 1975-1982) d'autre part, se renforcent. De forts risques de chômage pèsent sur les hommes employés dans les secteurs du commerce de détail et hôtellerie, du bâtiment et travaux publics, de la boulangeriepâtisserie, du textile, habillement et cuir (cf. annexe II). La dégradation, relevée plus haut, des chances de promotion dans la construction automobile ne s'accompagne pas de risques de chômage accrus dans ce secteur qui est, à cet égard, relativement protégé. Pour les femmes, tous les secteurs industriels sont porteurs de risques de chômage importants ; dans le tertiaire, il en va de même dans le commerce, la réparation et le commerce automobile, les hôtels, cafés et restaurants.

Les étrangers sont un peu plus exposés au chômage que les Français de naissance, mais l'écart n'est statistiquement significatif qu'à l'échelon du fichier réunissant les trois périodes étudiées (Échardour et Maurin, 1993). La situation des Français par acquisition est pratiquement identique à celle des Français de naissance.

Dans les années 1968-1975, les employés et ouvriers de l'agglomération parisienne étaient,

\section{Tableau 8}

Effet net du genre sur le risque de chômage

\begin{tabular}{|l|l|c|c|c|}
\hline & & $1968-1975$ & $1975-1982$ & $1982-1990$ \\
\hline $\begin{array}{l}\text { Risque de chômage } \\
\text { (en \%) }\end{array}$ & masculin observé & 1,7 & 4,8 & 5,9 \\
& féminin observé & 3,3 & 7,3 & 9,7 \\
& féminin calculé & 3,7 & 9,4 & 12,8 \\
\hline Indice & masculin observé & 100 & 100 & 100 \\
& féminin observé & 194 & 152 & 164 \\
& féminin calculé & 218 & 196 & 216 \\
\hline
\end{tabular}

Source : Échantillon démographique permanent, Insee. 
comme leurs homologues des grandes villes de province, exposés à des risques de chômage relativement élevés. Ce handicap relatif a disparu, et en 1990 la part de chômeurs est un peu plus faible, toutes choses égales d'ailleurs, dans l'agglomération parisienne que dans les communes rurales. C'est dans les agglomérations de province de plus de 100000 habitants que la situation est la plus défavorable.

\section{De moins en moins d'employées et d'ouvrières deviennent femmes au foyer}

$\mathrm{L}$ es femmes relativement jeunes sont de moins en moins nombreusesà quitter la

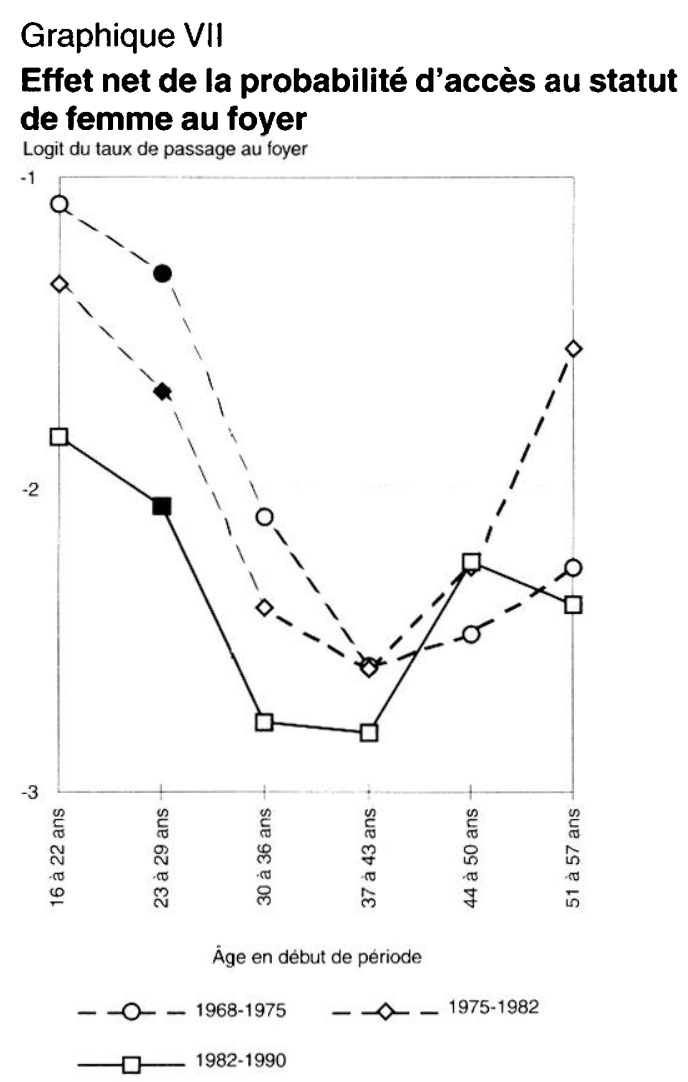

Symboles noirs : situation de référence. Source : Échantillon démographique permanent, Insee. population active. Certes, les évolutions nettes sont moins accentuées que les évolutions brutes. En effet, ces dernières traduisent notamment l'élévation du niveau de formation des femmes et les diplômées abandonnent moins volontiers leur emploi que les non-diplômées. $22 \%$ des employées et ouvrières en emploi en 1968 étaient au foyer en 1975 ; le taux net d'effets de structure s'élève à $20 \%$. Pour la période 1975-1982, le taux brut est de $17 \%$. Il passe à $12 \%$ pour 1982-1990 et le taux net est de $13,7 \%$ (cf. tableau 1 et annexe II).

Entre les deux premières périodes, les passages au foyer concernent des femmes de moins en moins jeunes. Au cours de la dernière période, la diminution du taux concerne toutes les tranches d'âge à l'exception des femmes âgées d'environ 47 ans en 1982 (cf. graphique VII).

Moins la femme est diplômée, plus elle a de « chances » de devenir femme au foyer. Cet effet s'atténue de période en période. L'écart, notamment, entre les titulaires d'un CAP ou d'un BEP et les femmes moins diplômées s'amenuise, de sorte qu'en 1990, la différence majeure se situe entre les plus diplômées (titulaires du baccalauréat ou d'un niveau équivalent) et les autres.

Au regard des taux de passage au foyer, au long des trois périodes observées, les différentes catégories socioprofessionnelles se répartissent en trois groupes. À un pôle, les employées de la Fonction publique se distinguent par une grande continuité de leur vie professionnelle ; inversement, les employées de commerce, les ouvrières et, surtout, les femmes au service direct des particuliers sont nombreuses à cesser d'exercer une activité professionnelle. Les employées administratives d'entreprises ont une position intermédiaire.

Les employées et ouvrières de l'agglomération parisienne ont des carrières professionnelles nettement plus continues que celles de leurs homologues de province. La mobilité géographique vient majorer sensiblement les « chances » (ou les risques) de passage au foyer ; son rôle s'amenuise dans les années 80 . 


\section{BIBLIOGRAPHIE}

Bayet A. et Julhès M. (1996), « Séries longues sur les salaires », Insee Résultats, n 457.

Bégué J. (1971), « Les déclarations de diplômes au recensement de la population en 1962 et $1968 »$, note $n^{\circ} 1915 / 433$, Insee.

Béret P. (1992), « Salaires et marchés internes : quelques évolutions récentes en France », Économie appliquée, $n^{\circ}$ XLV-2, p. 5-22.

Chauvel L. (1997), Évolution du svstème de stratification sociale et succession des cohortes. Grandeur et décadence des générations dans la société française des Trente glorieuses à nos jours, thèse, Université des Sciences et Technologies de Lille.

Chenu A. (1992), «Itinéraires socioprofessionnels et mobilité sectorielle », in Cheminements professionnels et mobilités sociales, Dubar C. et Coutrot L., La Documentation Française, p. 113-142.

Chenu A. (1993a). " Une classe ouvrière en crise », La société française. Données sociales 1993, p. 476-485

Chenu A. (1993b), « Les ouvriers et leurs carrières, enracinements et mobilités », Sociétés contemporaines, $\mathrm{n}^{\circ} 14-15$, p. $79-92$.

Chenu A. et Tabard N. (1993), "Les transformations socioprofessionnelles du territoire français, 1982. $1990 »$, Population, $n^{\circ}$ 6. p. 1735-1770.

Echardour A. et Maurin E. (1993), « La main-d'œuvre étrangère ", La société française. Données sociales 1993, p. 504-511.
Goux D. (1991), « Coup de frein sur les carrières 》, Économie et Statistique, $n^{\circ} 249$, p. 75-87.

Insee (1997), « Revenus et patrimoine des ménages, édition 1997 », Synthèses, $\mathrm{n}^{\circ} 11$.

Laulhé P. (1988), « Se mettre à son compte : des installations plus nombreuses, mais plus fragiles », Économie et Statistique, $\mathrm{n}^{\circ} 209$, p. 23-32.

Rouault D. (1995), «L'échantillon démographique permanent a pris un coup de jeune », Courrier des statistiques, $\mathrm{n}^{\circ} 73$, p. $35-41$.

Sautory O. (1987), "L’échantillon démographique permanent de l'Insee ". Courrier des statistiques, $n^{\circ} 41$, p. $1-4$.

Sautory O. (1987), «Étude sur les déclarations de diplômes aux recensements de la population de 1975 et 1982, réalisée à l'aide de l'échantillon démographique permanent ", département Populations et ménages, note $n^{\circ} 512 / 424$, Insee.

Singly F. de (1982), « Mariage, dot scolaire et position sociale ", Économie et Statistique, n ${ }^{\circ}$ 142, p. 7-20.

Vallet L.-A. (1995), « Diplôme féminin et carrière masculine : le sens d'une corrélation ". Revue française

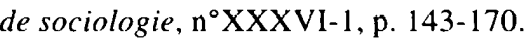

Vallet L.-A. et Caille J.-P. (1995), « Les carrières scolaires au collège des élèves étrangers ou issus de l'immigration », Éducation et formations, $\mathrm{n}^{\circ} 40$, p. 5-14. 
AnneXe I - DEVENIR DES OUVRIERS ET EMPLOYÉS

Tableau A

Coefficients de régression avec prise en compte de la situation matrimoniale A-1 Hommes

\begin{tabular}{|c|c|c|c|c|c|c|c|c|c|c|c|c|c|c|c|c|c|}
\hline & & \multicolumn{16}{|c|}{ Situation en fin de période intercensitaire } \\
\hline & & \multicolumn{4}{|c|}{ Cadre ou profession intermédiare } & \multicolumn{4}{|c|}{ À son compte } & \multicolumn{4}{|c|}{$\begin{array}{l}\text { Cadre, profession intermédiaire } \\
\text { ou à son compte }\end{array}$} & \multicolumn{4}{|c|}{ Chômage } \\
\hline & & $68-75$ & $75-82$ & $82-90$ & 3 périodes & $68-75$ & $75-82$ & $82-90$ & 3 périodes & $68-75$ & $75-82$ & $82-90$ & 3 périodes & $68-75$ & $75-82$ & $82-90$ & 3 périodes \\
\hline Situation de référence & & $-3,28$ & $-3,51$ & $-3,23$ & $-3,39$ & $-3,59$ & $-3,60$ & $-3,68$ & $-3,64$ & $-2,65$ & $-2,81$ & $-2,70$ & $-2,77$ & $-4,22$ & $-2,76$ & $-2,47$ & $-2,83$ \\
\hline Âge & $\begin{array}{l}16 \text { à } 22 \text { ans } \\
23 \text { à } 29 \text { ans } \\
30 \text { ̀̀ } 36 \text { ans } \\
37 \text { ̀̀ } 43 \text { ans } \\
44 \text { à } 50 \text { ans } \\
51 \text { à } 57 \text { ans }\end{array}$ & $\begin{array}{c}-0,09 \\
\text { Réf. } \\
-0,21 \\
-0,37 \\
-0,71 \\
-1,10 \\
\end{array}$ & $\begin{array}{c}-0,32 \\
\text { Réf. } \\
0,09 \\
\text { n.s. } \\
-0,17 \\
-0,44 \\
\end{array}$ & $\begin{array}{c}-0,15 \\
\text { Réf. } \\
0,13 \\
0,14 \\
\text { n.s. } \\
-0,28 \\
\end{array}$ & $\begin{array}{c}-0,16 \\
\text { Réf. } \\
\text { n.s. } \\
-0,07 \\
-0,29 \\
-0,62 \\
\end{array}$ & $\begin{array}{c}-0,27 \\
\text { Réf. } \\
-0,31 \\
-0,76 \\
-1,21 \\
-1,22 \\
\end{array}$ & $\begin{array}{c}-0,23 \\
\text { Réf. } \\
-0,28 \\
-0,69 \\
-1,16 \\
-1,49 \\
\end{array}$ & 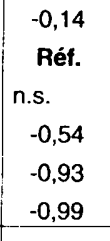 & $\begin{array}{c}-0,20 \\
\text { Réf. } \\
-0,22 \\
-0,67 \\
-1,09 \\
-1,26 \\
\end{array}$ & $\begin{array}{c}-0,17 \\
\text { Réf. } \\
-0,28 \\
-0,54 \\
-0,91 \\
-1,22 \\
\end{array}$ & $\begin{array}{c}-0,32 \\
\text { Réf. } \\
\text { n.s. } \\
-0,25 \\
-0,48 \\
-0,75 \\
\end{array}$ & $\begin{array}{c}-0,16 \\
\text { Réf. } \\
0,08 \\
\text { n.s. } \\
-0,27 \\
-0,48 \\
\end{array}$ & $\begin{array}{l}-0,19 \\
\text { Rét. } \\
-0,06 \\
-0,27 \\
-0,54 \\
-0,84 \\
\end{array}$ & $\begin{array}{l}0,05 \\
\text { Réf. } \\
\text { n.s. } \\
\text { n.s. } \\
0,38 \\
1,21\end{array}$ & $\begin{array}{l}0,17 \\
\text { Réf. } \\
\text { n.s. } \\
\text { n.s. } \\
0,27 \\
1,24\end{array}$ & $\begin{array}{l}\text { n.s. } \\
\text { Réf. } \\
\text { n.s. } \\
0,27 \\
0,86 \\
1,16 \\
\end{array}$ & $\begin{array}{l}\text { n.s. } \\
\text { Réf. } \\
\text { n.s. } \\
0,15 \\
0,56 \\
1,24 \\
\end{array}$ \\
\hline Période & $\begin{array}{l}1968-1975 \\
1975-1982 \\
1982-1990 \\
\end{array}$ & $\begin{array}{l}\text { III } \\
\prime \prime \prime \\
\prime \prime \prime\end{array}$ & $\begin{array}{l}\text { III } \\
\text { III } \\
\text { III }\end{array}$ & $\begin{array}{l}\text { III } \\
\text { III } \\
\text { III }\end{array}$ & $\begin{array}{l}-0,05 \\
\text { Réf. } \\
0,16 \\
\end{array}$ & $\begin{array}{l}\text { III } \\
\text { III } \\
\text { III }\end{array}$ & $\begin{array}{l}\text { III } \\
\prime \prime \prime \\
\prime \prime \prime\end{array}$ & $\begin{array}{l}\text { III } \\
\text { III } \\
\text { III }\end{array}$ & $\begin{array}{l}0,01 \\
\text { Réf. } \\
-0,08\end{array}$ & $\begin{array}{l}\prime \prime \prime \\
\prime \prime \prime \\
\text { III }\end{array}$ & $\begin{array}{l}\prime \prime \prime \\
11 \prime \\
I I I\end{array}$ & $\begin{array}{l}\prime \prime \prime \\
\prime \prime \prime \\
\prime \prime \prime \\
\end{array}$ & $\begin{array}{l}\text { n.s. } \\
\text { Réf. } \\
0,10 \\
\end{array}$ & $\begin{array}{l}\prime \prime \prime \\
\prime \prime \prime \\
\prime \prime \prime\end{array}$ & $\begin{array}{l}\text { III } \\
\text { III } \\
\text { III }\end{array}$ & $\begin{array}{l}\text { III } \\
\text { III } \\
\text { III }\end{array}$ & $\begin{array}{l}-1,21 \\
\text { Rét. } \\
0,35 \\
\end{array}$ \\
\hline Diplôme & $\begin{array}{l}\text { Sans diplôme, non déclaré } \\
\text { CEP } \\
\text { CAP, BEP ou équivalent } \\
\text { Supérieur au CAP-BEP }\end{array}$ & $\begin{array}{l}\text { Réf. } \\
0,94 \\
1,20 \\
2,28 \\
\end{array}$ & $\begin{array}{l}\text { Réf. } \\
0,83 \\
1,23 \\
2,29 \\
\end{array}$ & $\begin{array}{l}\text { Réf. } \\
0,41 \\
0,90 \\
2,00\end{array}$ & $\begin{array}{l}\text { Réf. } \\
0,75 \\
1,12 \\
2,18\end{array}$ & $\begin{array}{l}\text { Réf. } \\
0,51 \\
0,79 \\
0,91\end{array}$ & $\begin{array}{l}\text { Réf. } \\
0,48 \\
0,83 \\
0,94 \\
\end{array}$ & $\begin{array}{l}\text { Réf. } \\
0,25 \\
0,60 \\
0,93 \\
\end{array}$ & $\begin{array}{l}\text { Réf. } \\
0,45 \\
0,76 \\
0,96 \\
\end{array}$ & $\begin{array}{l}\text { Réf. } \\
0,79 \\
1,09 \\
2,03\end{array}$ & $\begin{array}{l}\text { Réf. } \\
0,72 \\
1,14 \\
2,05 \\
\end{array}$ & $\begin{array}{l}\text { Réf. } \\
0,36 \\
0,85 \\
1,87 \\
\end{array}$ & $\begin{array}{l}\text { Réf. } \\
0,65 \\
1,04 \\
1,98 \\
\end{array}$ & $\begin{array}{l}-0,24 \\
-0,43 \\
\text { n.s. } \\
\end{array}$ & $\begin{array}{r}\text { Réf. } \\
-0,25 \\
-0,50 \\
-0,42 \\
\end{array}$ & $\begin{array}{c}\text { Réf. } \\
-0,23 \\
-0,52 \\
-0,64 \\
\end{array}$ & $\begin{array}{c}\text { Réf. } \\
-0,23 \\
-0,49 \\
-0,49 \\
\end{array}$ \\
\hline Situation matrimoniale & $\begin{array}{l}\text { Célibataire } \\
\text { Marié } \\
\text { Veuf, divorcé }\end{array}$ & $\begin{array}{l}-0,41 \\
\text { Réf. } \\
-0,35\end{array}$ & $\begin{array}{l}-0,34 \\
\text { Réf. } \\
\text { n.s. } \\
\end{array}$ & $\begin{array}{c}-0,31 \\
\text { Réf. } \\
-0,28 \\
\end{array}$ & $\begin{array}{l}-0,35 \\
\text { Réf. } \\
-0,24 \\
\end{array}$ & $\begin{array}{l}-0,33 \\
\text { Réf. } \\
\text { n.s. }\end{array}$ & $\begin{array}{l}-0,31 \\
\text { Réf. } \\
\text { n.s. }\end{array}$ & $\begin{array}{l}-0,20 \\
\text { Réf. } \\
\text { n.s. }\end{array}$ & $\begin{array}{l}-0,28 \\
\text { Réf. } \\
\text { n.s. }\end{array}$ & $\begin{array}{l}-0,42 \\
\text { Réf. } \\
-0,30 \\
\end{array}$ & $\begin{array}{l}-0,37 \\
\text { Réf. } \\
\text { n.s. }\end{array}$ & $\begin{array}{l}-0,31 \\
\text { Réf. } \\
-0,22 \\
\end{array}$ & $\begin{array}{c}-0,36 \\
\text { Réf. } \\
-0,18 \\
\end{array}$ & $\begin{array}{l}0,65 \\
\text { Réf. } \\
1,06 \\
\end{array}$ & $\begin{array}{l}0,68 \\
\text { Réf. } \\
0,79 \\
\end{array}$ & $\begin{array}{l}0,62 \\
\text { Réf. } \\
0,86 \\
\end{array}$ & $\begin{array}{l}0,64 \\
\text { Réf. } \\
0,88\end{array}$ \\
\hline Mobilité géographique & $\begin{array}{l}\text { Même département } \\
\text { Dép. différents aux } 2 \text { recens. }\end{array}$ & $\begin{array}{l}\text { Réf. } \\
0,37\end{array}$ & $\begin{array}{l}\text { Réf. } \\
0,33\end{array}$ & $\begin{array}{l}\text { Réf. } \\
0,45\end{array}$ & $\begin{array}{l}\text { Réf. } \\
0,38\end{array}$ & $\begin{array}{l}\text { Réf. } \\
0,47\end{array}$ & $\begin{array}{l}\text { Réf. } \\
0,54\end{array}$ & $\begin{array}{r}\text { Réf. } \\
0,56 \\
\end{array}$ & $\begin{array}{l}\text { Réf. } \\
0,52\end{array}$ & $\begin{array}{l}\text { Réf. } \\
0,44\end{array}$ & $\begin{array}{l}\text { Réf. } \\
0,43\end{array}$ & $\begin{array}{l}\text { Réf. } \\
0,54\end{array}$ & $\begin{array}{l}\text { Réf. } \\
0,46\end{array}$ & $\begin{array}{l}\text { Réf. } \\
0,39\end{array}$ & $\begin{array}{l}\text { Réf. } \\
0,36\end{array}$ & $\begin{array}{l}\text { Réf. } \\
0,56 \\
\end{array}$ & $\begin{array}{l}\text { Réf. } \\
0,45\end{array}$ \\
\hline Secteur d’activité & $\begin{array}{l}\text { Industrie } \\
\text { Tertiaire }\end{array}$ & $\begin{array}{c}\text { Réf. } \\
-0,20\end{array}$ & $\begin{array}{c}\text { Réf. } \\
-0,14\end{array}$ & $\begin{array}{c}\text { Réf. } \\
-0,12\end{array}$ & $\begin{array}{l}\text { Réf. } \\
-0,15 \\
\end{array}$ & $\begin{array}{l}\text { Réf. } \\
0,27\end{array}$ & $\begin{array}{l}\text { Réf. } \\
0,13 \\
\end{array}$ & $\begin{array}{l}\text { Réf. } \\
\text { n.s. }\end{array}$ & $\begin{array}{l}\text { Réf. } \\
0,15\end{array}$ & $\begin{array}{l}\text { Réf. } \\
\text { n.s. }\end{array}$ & $\begin{array}{l}\text { Réf. } \\
-0,07\end{array}$ & $\begin{array}{c}\text { Réf. } \\
-0,07\end{array}$ & $\begin{array}{l}\text { Réf. } \\
-0,07\end{array}$ & $\begin{array}{l}\text { Réf. } \\
-0,27\end{array}$ & $\begin{array}{c}\text { Réf. } \\
-0,45 \\
\end{array}$ & $\begin{array}{c}\text { Réf. } \\
-0,25\end{array}$ & $\begin{array}{l}\text { Réf. } \\
-0,34 \\
\end{array}$ \\
\hline Nationalité & $\begin{array}{l}\text { Français de naissance } \\
\text { Français par acquisition } \\
\text { Étranger }\end{array}$ & $\begin{array}{c}\text { Réf. } \\
\text { n.s. } \\
-0,68 \\
\end{array}$ & $\begin{array}{c}\text { Réf. } \\
\text { n.s. } \\
-0,61 \\
\end{array}$ & $\begin{array}{l}\text { Réf. } \\
-0,22 \\
-0,70 \\
\end{array}$ & $\begin{array}{c}\text { Réf. } \\
\text { n.s. } \\
-0,66\end{array}$ & $\begin{array}{l}\text { Réf. } \\
\text { n.s. } \\
\text { n.s. }\end{array}$ & $\begin{array}{l}\text { Réf. } \\
0,27 \\
\text { n.s. }\end{array}$ & $\begin{array}{l}\text { Réf. } \\
\text { n.s. } \\
0,71\end{array}$ & $\begin{array}{l}\text { Réf. } \\
\text { n.s. } \\
0,30 \\
\end{array}$ & $\begin{array}{c}\text { Réf. } \\
\text { n.s. } \\
-0,42 \\
\end{array}$ & $\begin{array}{c}\text { Réf. } \\
\text { n.s. } \\
-0,39 \\
\end{array}$ & $\begin{array}{c}\text { Réf. } \\
-0,17 \\
-0,15 \\
\end{array}$ & $\begin{array}{c}\text { Réf. } \\
\text { n.s. } \\
-0,31 \\
\end{array}$ & $\begin{array}{l}\text { Réf. } \\
\text { n.s. } \\
0,15 \\
\end{array}$ & $\begin{array}{l}\text { Réf. } \\
\text { n.s. } \\
0,25 \\
\end{array}$ & $\begin{array}{l}\text { Réf. } \\
\text { n.s. } \\
0,15 \\
\end{array}$ & $\begin{array}{l}\text { Réf. } \\
\text { n.s. } \\
0,20\end{array}$ \\
\hline $\begin{array}{l}\text { Catégories } \\
\text { socioprofessionnelles }\end{array}$ & $\begin{array}{l}\text { Employé qualifié } \\
\text { Employé non qualifié } \\
\text { Ouvrier qualifié } \\
\text { Ouvrier non qualifié }\end{array}$ & $\begin{array}{l}0,88 \\
0,87 \\
0,53 \\
\text { Réf. }\end{array}$ & $\begin{array}{l}0,78 \\
0,92 \\
0,72 \\
\text { Réf. }\end{array}$ & $\begin{array}{l}1,03 \\
1,10 \\
0,58 \\
\text { Réf. }\end{array}$ & $\begin{array}{l}0,91 \\
0,98 \\
0,61 \\
\text { Réf. }\end{array}$ & $\begin{array}{r}-1,25 \\
1,46 \\
0,37 \\
\text { Réf. } \\
\end{array}$ & $\begin{array}{r}-1,59 \\
1,04 \\
0,33 \\
\text { Réf. } \\
\end{array}$ & $\begin{array}{r}-1,31 \\
0,99 \\
0,35 \\
\text { Réf. }\end{array}$ & $\begin{array}{r}-1,38 \\
1,18 \\
0,36 \\
\text { Réf. } \\
\end{array}$ & $\begin{array}{l}0,51 \\
1,31 \\
0,50 \\
\text { Réf. }\end{array}$ & $\begin{array}{l}0,32 \\
1,10 \\
0,61 \\
\text { Réf. }\end{array}$ & $\begin{array}{l}0,65 \\
1,23 \\
0,54 \\
\text { Réf. }\end{array}$ & $\begin{array}{l}0,51 \\
1,22 \\
0,55 \\
\text { Réf. }\end{array}$ & $\begin{array}{l}-0,91 \\
0,33 \\
\text { n.s. } \\
\text { Réf. }\end{array}$ & $\begin{array}{c}-0,76 \\
\text { n.s. } \\
-0,15 \\
\text { Rét. }\end{array}$ & $\begin{array}{r}-1,05 \\
0,45 \\
-0,28 \\
\text { Réf. } \\
\end{array}$ & $\begin{array}{r}-0,91 \\
0,34 \\
-0,18 \\
\text { Réf. }\end{array}$ \\
\hline Tranche d'unité urbaine & $\begin{array}{l}\text { Communes rurales } \\
\text { UU } 2000 \text { à } 99999 \text { habitants } \\
\text { UU } 100000 \text { à } 1999999 \mathrm{~h} \text {. } \\
\text { Agglomération parisienne }\end{array}$ & $\begin{array}{c}-0,42 \\
-0,19 \\
\text { Réf. } \\
0,13 \\
\end{array}$ & $\begin{array}{c}-0,33 \\
-0,18 \\
\text { Réf. } \\
0,13\end{array}$ & $\begin{array}{c}-0,27 \\
-0,12 \\
\text { Réf. } \\
0,28 \\
\end{array}$ & $\begin{array}{c}-0,34 \\
-0,16 \\
\text { Réf. } \\
0,18 \\
\end{array}$ & $\begin{array}{l}0,38 \\
\text { n.s. } \\
\text { Rét. } \\
-0,20 \\
\end{array}$ & $\begin{array}{l}0,35 \\
0,14 \\
\text { Réf. } \\
\text { n.s. }\end{array}$ & $\begin{array}{c}0,24 \\
\text { n.s. } \\
\text { Réf. } \\
\text { n.s. }\end{array}$ & $\begin{array}{c}0,33 \\
0,10 \\
\text { Réf. } \\
-0,11 \\
\end{array}$ & $\begin{array}{l}-0,15 \\
-0,12 \\
\text { Réf. } \\
\text { n.s. }\end{array}$ & $\begin{array}{l}-0,11 \\
-0,09 \\
\text { Rét. } \\
\text { n.s. }\end{array}$ & $\begin{array}{l}-0,14 \\
-0,09 \\
\text { Réf. } \\
0,23\end{array}$ & $\begin{array}{c}-0,13 \\
-0,10 \\
\text { Réf. } \\
0,12 \\
\end{array}$ & $\begin{array}{l}-0,45 \\
-0,24 \\
\text { Réf. } \\
\text { n.s. }\end{array}$ & $\begin{array}{l}-0,53 \\
-0,25 \\
\text { Réf. } \\
-0,21 \\
\end{array}$ & $\begin{array}{l}-0,50 \\
-0,27 \\
\text { Réf. } \\
-0,44 \\
\end{array}$ & $\begin{array}{r}-0,51 \\
-0,26 \\
\text { Réf. } \\
-0,24 \\
\end{array}$ \\
\hline
\end{tabular}


Annexe I (fin) - DEVENIR DES OUVRIERS ET EMPLOYÉS

Coefficients de régression avec prise en compte de la situation matrimoniale

A-2 Femmes

\begin{tabular}{|c|c|c|c|c|c|c|c|c|c|c|c|c|c|c|c|c|c|}
\hline & & \multicolumn{15}{|c|}{ Situation en fin de période intercensitaire } & \multirow[b]{3}{*}{3 périodes } \\
\hline & & \multicolumn{4}{|c|}{ Cadre ou profession intermédiaire } & \multicolumn{4}{|c|}{ À son compte } & \multicolumn{4}{|c|}{$\begin{array}{l}\text { Cadre, profession intermédiaire } \\
\text { ou à son compte }\end{array}$} & \multicolumn{3}{|c|}{ Chômage } & \\
\hline & & $68-75$ & $75-82$ & $82-90$ & 3 périodes & $68-75$ & $75-82$ & $82-90$ & 3 périodes & $68-75$ & $75-82$ & $82-90$ & 3 périodes & $68-75$ & $75-82$ & $82-90$ & \\
\hline \multicolumn{2}{|l|}{ Situation de référence } & $-4,70$ & $-4,69$ & $-4,38$ & $-4,72$ & $-4,40$ & $-4,81$ & $-4,66$ & $-4,83$ & $-3,96$ & $-4,10$ & $-3,85$ & $-4,16$ & $-3,00$ & $-2,01$ & $-1,48$ & $-1,98$ \\
\hline Âge & $\begin{array}{l}16 \text { à } 22 \text { ans } \\
23 \text { d̀ } 29 \text { ans } \\
30 \text { dे } 36 \text { ans } \\
37 \text { à } 43 \text { ans } \\
44 \text { dे } 50 \text { ans } \\
51 \text { dे } 57 \text { ans } \\
\end{array}$ & $\begin{array}{c}-0,39 \\
\text { Rét. } \\
\text { n.s. } \\
\text { n.s. } \\
-0,38 \\
-0,39 \\
\end{array}$ & $\begin{array}{l}-0,43 \\
\text { Réf. } \\
\text { n.s. } \\
\text { n.s. } \\
\text { n.s. } \\
\text { n.s. }\end{array}$ & $\begin{array}{l}-0,33 \\
\text { Réf. } \\
0,35 \\
0,36 \\
0,25 \\
\text { n.s. } \\
\end{array}$ & $\begin{array}{l}-0,35 \\
\text { Réf. } \\
0,21 \\
0,14 \\
\text { n.s. } \\
\text { n.s. } \\
\end{array}$ & $\begin{array}{c}-0,43 \\
\text { Réf. } \\
-0,53 \\
-0,64 \\
-1,09 \\
-1,46 \\
\end{array}$ & \begin{tabular}{c|}
$-0,03$ \\
Réf. \\
0,14 \\
$-0,26$ \\
$-0,63$ \\
$-0,75$ \\
\end{tabular} & $\begin{array}{l}0,08 \\
\text { Réf. } \\
\text { n.s. } \\
0,34 \\
\text { n.s. } \\
\text { n.s. }\end{array}$ & $\begin{array}{c}-0,11 \\
\text { Réf. } \\
\text { n.s. } \\
\text { n.s. } \\
-0,61 \\
-0,77 \\
\end{array}$ & $\begin{array}{c}-0,42 \\
\text { Rét. } \\
\text { n.s. } \\
-0,17 \\
-0,57 \\
-0,66 \\
\end{array}$ & $\begin{array}{c}-0,37 \\
\text { Reff. } \\
\text { n.s. } \\
\text { n.s. } \\
\text { n.s. } \\
-0,22 \\
\end{array}$ & $\begin{array}{l}-0,28 \\
\text { Réf. } \\
0,33 \\
0,37 \\
0,18 \\
\text { n.s. } \\
\end{array}$ & $\begin{array}{c}-0,31 \\
\text { Réf. } \\
0,18 \\
0,10 \\
-0,09 \\
-0,19 \\
\end{array}$ & $\begin{array}{c}0,31 \\
\text { Réf. } \\
-0,37 \\
-0,56 \\
\text { n.s. } \\
\text { n.s. }\end{array}$ & \begin{tabular}{c|}
0,26 \\
Réf. \\
$-0,26$ \\
$-0,42$ \\
0,16 \\
0,73 \\
\end{tabular} & \begin{tabular}{c|}
0,17 \\
Réf. \\
$-0,27$ \\
$-0,26$ \\
0,30 \\
0,33 \\
\end{tabular} & \begin{tabular}{r|}
0,24 \\
Réf. \\
$-0,28$ \\
$-0,35$ \\
0,20 \\
0,51 \\
\end{tabular} \\
\hline Période & $\begin{array}{l}1968-1975 \\
1975-1982 \\
1982-1990 \\
\end{array}$ & $\begin{array}{l}\prime \prime \prime \\
\prime \prime \prime \\
\prime \prime \prime\end{array}$ & III & 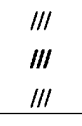 & $\begin{array}{l}-0,14 \\
\text { Réf. } \\
0,46\end{array}$ & $\begin{array}{l}\text { III } \\
\text { III } \\
\prime \prime \prime\end{array}$ & $\begin{array}{l}\text { III } \\
\text { III } \\
\text { III }\end{array}$ & $\begin{array}{l}\text { III } \\
\text { III } \\
\text { III }\end{array}$ & $\begin{array}{l}0,28 \\
\text { Réf. } \\
\text { n.s. }\end{array}$ & $\begin{array}{l}\prime \prime \prime \prime \\
\prime \prime \prime \\
\prime \prime \prime\end{array}$ & $\begin{array}{l}\text { III } \\
\text { III } \\
\text { III }\end{array}$ & $\begin{array}{l}\text { III } \\
\text { III } \\
\text { III }\end{array}$ & $\begin{array}{l}\text { n.s. } \\
\text { Réf. } \\
0,40 \\
\end{array}$ & $\begin{array}{l}\prime \prime \prime \\
\prime \prime \prime \\
I I \prime\end{array}$ & $\begin{array}{l}\prime \prime \prime \\
\prime \prime \prime \\
\prime \prime \prime\end{array}$ & $\begin{array}{l}\prime \prime \prime \\
\prime \prime \prime \\
\prime \prime \prime\end{array}$ & $\begin{array}{l}-1,18 \\
\text { Réf. } \\
0,49 \\
\end{array}$ \\
\hline Diplôme & $\begin{array}{l}\text { Sans diplôme, non déclaré } \\
\text { CEP } \\
\text { CAP, BEP ou équivalent } \\
\text { Supérieur au CAP-BEP }\end{array}$ & $\begin{array}{l}\text { Réf. } \\
1,11 \\
1,43 \\
2,38\end{array}$ & $\begin{array}{l}\text { Réf. } \\
0,76 \\
1,11 \\
1,95\end{array}$ & $\begin{array}{l}\text { Réf. } \\
0,39 \\
0,93 \\
2,00 \\
\end{array}$ & $\begin{array}{l}\text { Réf. } \\
0,69 \\
1,09 \\
2,04 \\
\end{array}$ & $\begin{array}{l}\text { Réf. } \\
0,55 \\
0,96 \\
1,61 \\
\end{array}$ & $\begin{array}{l}\text { Réf. } \\
0,53 \\
0,50 \\
1,13 \\
\end{array}$ & $\begin{array}{l}\text { Réf. } \\
0,17 \\
\text { n.s. } \\
1,02 \\
\end{array}$ & $\begin{array}{l}\text { Réf. } \\
0,47 \\
0,86 \\
1,25 \\
\end{array}$ & $\begin{array}{l}\text { Réf. } \\
0,90 \\
1,26 \\
2,18 \\
\end{array}$ & $\begin{array}{l}\text { Réf. } \\
0,70 \\
0,97 \\
1,81\end{array}$ & $\begin{array}{l}\text { Réf. } \\
0,33 \\
0,91 \\
1,88\end{array}$ & $\begin{array}{l}\text { Réf. } \\
0,62 \\
1,02 \\
1,90 \\
\end{array}$ & $\begin{array}{c}\text { Réf. } \\
\text { n.s. } \\
\text { n.s. } \\
-0,30\end{array}$ & $\begin{array}{c}\text { Réf. } \\
\text { n.s. } \\
\text { n.s. } \\
-0,21\end{array}$ & $\begin{array}{c}\text { Réf. } \\
-0,13 \\
\text { n.s. } \\
-0,45 \\
\end{array}$ & $\begin{array}{c}\text { Rét. } \\
\text { n.s. } \\
\text { n.s. } \\
-0,33\end{array}$ \\
\hline Situation matrimoniale & $\begin{array}{l}\text { Célibataire } \\
\text { Marié } \\
\text { Veuf, divorcé }\end{array}$ & $\begin{array}{l}0,18 \\
\text { Réf. } \\
\text { n.s. }\end{array}$ & $\begin{array}{l}0,12 \\
\text { Réf. } \\
\text { n.s. }\end{array}$ & $\begin{array}{l}0,16 \\
\text { Réf. } \\
\text { n.s. }\end{array}$ & $\begin{array}{l}0,16 \\
\text { Réf. } \\
\text { n.s. }\end{array}$ & $\begin{array}{l}-0,60 \\
\text { Réf. } \\
\text { n.s. }\end{array}$ & $\begin{array}{c}-0,27 \\
\text { Réf. } \\
0,13\end{array}$ & $\begin{array}{l}-0,26 \\
\text { Réf. } \\
\text { n.s. }\end{array}$ & $\begin{array}{l}-0,37 \\
\text { Réf. } \\
\text { n.s. } \\
\end{array}$ & $\begin{array}{l}0,00 \\
\text { Réf. } \\
\text { n.s. }\end{array}$ & $\begin{array}{l}0,06 \\
\text { Rét. } \\
\text { n.s. }\end{array}$ & $\begin{array}{l}0,11 \\
\text { Réf. } \\
\text { n.s. }\end{array}$ & $\begin{array}{l}0,08 \\
\text { Réf. } \\
\text { n.s. }\end{array}$ & $\begin{array}{l}\text { n.s. } \\
\text { Réf. } \\
\text { n.s. }\end{array}$ & $\begin{array}{l}0,15 \\
\text { Rét. } \\
\text { n.s. }\end{array}$ & $\begin{array}{l}0,13 \\
\text { Réf. } \\
\text { n.s. }\end{array}$ & $\begin{array}{l}0,10 \\
\text { Réf. } \\
\text { n.s. }\end{array}$ \\
\hline Mobilité géographique & $\begin{array}{l}\text { Même département } \\
\text { Dép. différents aux } 2 \text { recens. }\end{array}$ & $\begin{array}{l}\text { Réf. } \\
0,33\end{array}$ & $\begin{array}{l}\text { Réf. } \\
0,40\end{array}$ & $\begin{array}{l}\text { Réf. } \\
0,54\end{array}$ & $\begin{array}{l}\text { Réf. } \\
0,44\end{array}$ & $\begin{array}{l}\text { Réf. } \\
0,58 \\
\end{array}$ & $\begin{array}{l}\text { Réf. } \\
0,80\end{array}$ & $\begin{array}{l}\text { Réf. } \\
0,81\end{array}$ & $\begin{array}{l}\text { Réf. } \\
0,72\end{array}$ & $\begin{array}{l}\text { Réf. } \\
0,41\end{array}$ & $\begin{array}{l}\text { Réf. } \\
0,49\end{array}$ & $\begin{array}{l}\text { Réf. } \\
0,60 \\
\end{array}$ & $\begin{array}{l}\text { Réf. } \\
0,52\end{array}$ & $\begin{array}{l}\text { Réf. } \\
0,94\end{array}$ & $\begin{array}{l}\text { Réf. } \\
1,13\end{array}$ & $\begin{array}{l}\text { Réf. } \\
1,22\end{array}$ & $\begin{array}{l}\text { Réf. } \\
1,13\end{array}$ \\
\hline Secteur d'activité & $\begin{array}{l}\text { Industrie } \\
\text { Tertiaire }\end{array}$ & $\begin{array}{l}\text { Réf. } \\
\text { n.s. }\end{array}$ & $\begin{array}{l}\text { Réf. } \\
-0,18\end{array}$ & $\begin{array}{l}\text { Réf. } \\
-0,43 \\
\end{array}$ & $\begin{array}{l}\text { Réf. } \\
-0,20\end{array}$ & $\begin{array}{l}\text { Réf. } \\
0,22\end{array}$ & $\begin{array}{l}\text { Réf. } \\
0,06\end{array}$ & $\begin{array}{l}\text { Réf. } \\
-0,31\end{array}$ & $\begin{array}{l}\text { Réf. } \\
\text { n.s. }\end{array}$ & $\begin{array}{l}\text { Réf. } \\
0,11\end{array}$ & $\begin{array}{l}\text { Réf. } \\
-0,15\end{array}$ & $\begin{array}{l}\text { Réf. } \\
-0,43\end{array}$ & $\begin{array}{l}\text { Réf. } \\
-0,17\end{array}$ & $\begin{array}{l}\text { Réf. } \\
\text { n.s. }\end{array}$ & $\begin{array}{l}\text { Réf. } \\
-0,64\end{array}$ & $\begin{array}{l}\text { Réf. } \\
-0,51\end{array}$ & $\begin{array}{l}\text { Réf. } \\
-0,52\end{array}$ \\
\hline Nationalité & $\begin{array}{l}\text { Français de naissance } \\
\text { Français par acquisition } \\
\text { Étranger }\end{array}$ & $\begin{array}{l}\text { Réf. } \\
\text { n.s. } \\
\text { n.s. }\end{array}$ & $\begin{array}{l}\text { Réf. } \\
\text { n.s. } \\
\text { n.s. }\end{array}$ & $\begin{array}{c}\text { Réf. } \\
\text { n.s. } \\
-0,60 \\
\end{array}$ & $\begin{array}{r}\text { Réf. } \\
0,15 \\
-0,34 \\
\end{array}$ & $\begin{array}{l}\text { Réf. } \\
\text { n.s. } \\
\text { n.s. }\end{array}$ & $\begin{array}{r}\text { Réf. } \\
0,39 \\
-1,15 \\
\end{array}$ & $\begin{array}{c}\text { Réf. } \\
\text { n.s. } \\
-0,30 \\
\end{array}$ & $\begin{array}{r}\text { Réf. } \\
0,17 \\
-0,54 \\
\end{array}$ & $\begin{array}{c}\text { Réf. } \\
\text { n.s. } \\
-0,21 \\
\end{array}$ & $\begin{array}{r}\text { Réf. } \\
0,26 \\
-0,35 \\
\end{array}$ & $\begin{array}{c}\text { Réf. } \\
\text { n.s. } \\
-0,58 \\
\end{array}$ & $\begin{array}{r}\text { Réf. } \\
0,16 \\
-0,45 \\
\end{array}$ & $\begin{array}{l}\text { Réf. } \\
\text { n.s. } \\
\text { n.s. }\end{array}$ & $\begin{array}{l}\text { Réf. } \\
\text { n.s. } \\
\text { n.s. }\end{array}$ & $\begin{array}{l}\text { Réf. } \\
\text { n.s. } \\
\text { n.s. }\end{array}$ & $\begin{array}{l}\text { Réf. } \\
\text { n.s. } \\
\text { n.s. }\end{array}$ \\
\hline $\begin{array}{l}\text { Catégories } \\
\text { socioprofessionnelles }\end{array}$ & $\begin{array}{l}\text { Employé qualifié } \\
\text { Employé non qualifié } \\
\text { Ouvrier qualifié } \\
\text { Ouvrier non qualifié }\end{array}$ & $\begin{array}{l}0,66 \\
\text { n.s. } \\
0,89 \\
\text { Réf. }\end{array}$ & $\begin{array}{l}1,18 \\
0,61 \\
1,32 \\
\text { Réf. }\end{array}$ & $\begin{array}{l}1,30 \\
0,65 \\
0,94 \\
\text { Réf. }\end{array}$ & $\begin{array}{l}1,06 \\
0,46 \\
1,02 \\
\text { Réf. }\end{array}$ & $\begin{array}{l}-0,81 \\
1,41 \\
0,85 \\
\text { Réf. }\end{array}$ & $\begin{array}{l}-0,77 \\
1,23 \\
0,45 \\
\text { Réf. }\end{array}$ & $\begin{array}{l}-0,76 \\
1,17 \\
\text { n.s. } \\
\text { Réf. }\end{array}$ & $\begin{array}{r}-0,79 \\
1,26 \\
0,44 \\
\text { Réf. }\end{array}$ & $\begin{array}{l}0,38 \\
0,75 \\
0,90 \\
\text { Réf. }\end{array}$ & $\begin{array}{l}0,80 \\
0,93 \\
1,08 \\
\text { Réf. }\end{array}$ & $\begin{array}{l}0,95 \\
0,92 \\
0,70 \\
\text { Réf. }\end{array}$ & $\begin{array}{l}0,73 \\
0,82 \\
0,86 \\
\text { Réf. }\end{array}$ & $\begin{array}{l}-0,52 \\
\text { n.s. } \\
\text { n.s. } \\
\text { Réf. }\end{array}$ & $\begin{array}{l}-0,66 \\
\text { n.s. } \\
-0,22 \\
\text { Réf. }\end{array}$ & $\begin{array}{r}-0,80 \\
0,19 \\
-0,20 \\
\text { Réf. }\end{array}$ & $\begin{array}{r}-0,72 \\
0,12 \\
-0,18 \\
\text { Réf. }\end{array}$ \\
\hline Tranche d'unité urbaine & $\begin{array}{l}\text { Communes rurales } \\
\text { UU } 2000 \text { à } 99999 \text { habitants } \\
\text { UU } 100000 \text { à } 1999999 \mathrm{~h} \text {. } \\
\text { Agglomération parisienne }\end{array}$ & $\begin{array}{c}\text { n.s. } \\
-0,19 \\
\text { Rét. } \\
0,17\end{array}$ & $\begin{array}{c}-0,26 \\
\text { n.s. } \\
\text { Réf. } \\
0,31\end{array}$ & $\begin{array}{l}-0,15 \\
-0,11 \\
\text { Rét. } \\
0,60\end{array}$ & $\begin{array}{c}-0,20 \\
-0,12 \\
\text { Réf. } \\
0,40 \\
\end{array}$ & $\begin{array}{c}\text { n.s. } \\
\text { n.s. } \\
\text { Réf. } \\
-0,28\end{array}$ & $\begin{array}{c}0,13 \\
-0,07 \\
\text { Réf. } \\
-0,31\end{array}$ & $\begin{array}{l}\text { n.s. } \\
\text { n.s. } \\
\text { Réf. } \\
-0,32\end{array}$ & $\begin{array}{l}\text { n.s. } \\
\text { n.s. } \\
\text { Réf. } \\
-0,29\end{array}$ & $\begin{array}{c}\text { n.s. } \\
-0,14 \\
\text { Réf. } \\
\text { n.s. }\end{array}$ & $\begin{array}{c}-0,17 \\
\text { n.s. } \\
\text { Réf. } \\
0,22\end{array}$ & $\begin{array}{c}-0,13 \\
\text { n.s. } \\
\text { Réf. } \\
0,52\end{array}$ & $\begin{array}{c}-0,14 \\
-0,09 \\
\text { Réf. } \\
0,31\end{array}$ & $\begin{array}{c}-0,59 \\
-0,21 \\
\text { Réf. } \\
\text { n.s. }\end{array}$ & $\begin{array}{c}-0,35 \\
-0,20 \\
\text { Réf. } \\
-0,33\end{array}$ & $\begin{array}{c}-0,25 \\
-0,13 \\
\text { Réf. } \\
-0,45\end{array}$ & $\begin{array}{c}-0,32 \\
-0,16 \\
\text { Réf. } \\
-0,35 \\
\end{array}$ \\
\hline
\end{tabular}

n.s. : écart à la situation de référence non significatif au seuil de 0,05 .

Source : Échantillon démographique permanent, Insee. 
Annexe II- DEVENIR DES OUVRIERS ET DES EMPLOYÉS

Tableau A - Coefficients de régression avec prise en compte des catégories socioprofessionnelles, de la mobilité et des secteurs détaillés A-1 Hommes

\begin{tabular}{|c|c|c|c|c|c|c|c|c|c|c|c|c|c|}
\hline & & \multicolumn{12}{|c|}{ Situation en fin de période intercensitaire } \\
\hline & & \multicolumn{4}{|c|}{ Cadre ou profession intermédiaire } & \multicolumn{4}{|c|}{ À son compte } & \multicolumn{4}{|c|}{ Chomâge } \\
\hline & & $68-75$ & $75-82$ & $82-90$ & 3 périodes & $68-75$ & $75-82$ & $82-90$ & 3 périodes & $68-75$ & $75-82$ & $82-90$ & 3 périodes \\
\hline \multicolumn{2}{|l|}{ Situation de référence } & $-1,35$ & $-1,29$ & $-1,55$ & $-1,44$ & $-4,05$ & $-4,42$ & $-4,15$ & $-4,11$ & $-5,06$ & $-3,59$ & $-3,35$ & $-3,68$ \\
\hline Âge & $\begin{array}{l}16 \text { à } 22 \text { ans } \\
23 \text { à } 29 \text { ans } \\
30 \text { à } 36 \text { ans } \\
37 \text { ̀̀ } 43 \text { ans } \\
44 \text { à } 50 \text { ans } \\
51 \text { à } 57 \text { ans }\end{array}$ & $\begin{array}{l}\text { n.s. } \\
\text { Réf. } \\
-0,21 \\
-0,39 \\
-0,73 \\
-1,11 \\
\end{array}$ & $\begin{array}{r}-0,32 \\
\text { Réf. } \\
\text { n.s. } \\
\text { n.s. } \\
-0,22 \\
-0,45 \\
\end{array}$ & $\begin{array}{r}-0,16 \\
\text { Réf. } \\
0,12 \\
0,14 \\
\text { n.s. } \\
-0,22 \\
\end{array}$ & $\begin{array}{r}-0,16 \\
\text { Réf. } \\
\text { n.s. } \\
-0,09 \\
-0,32 \\
-0,61 \\
\end{array}$ & $\begin{array}{r}-0,48 \\
\text { Réf. } \\
-0,17 \\
-0,50 \\
-0,93 \\
-1,01 \\
\end{array}$ & $\begin{array}{r}-0,47 \\
\text { Réf. } \\
\text { n.s. } \\
-0,37 \\
-0,75 \\
-1,12 \\
\end{array}$ & $\begin{array}{r}-0,37 \\
\text { Réf. } \\
\text { n.s. } \\
-0,37 \\
-0,75 \\
-0,88 \\
\end{array}$ & $\begin{array}{r}-0,45 \\
\text { Réf. } \\
\text { n.s. } \\
-0,42 \\
-0,80 \\
-1,02 \\
\end{array}$ & $\begin{array}{l}\text { n.s. } \\
\text { Réf. } \\
\text { n.s. } \\
0,25 \\
0,39 \\
1,23 \\
\end{array}$ & $\begin{array}{r}0,13 \\
\text { Réf. } \\
\text { n.s. } \\
\text { n.s. } \\
0,29 \\
1,22 \\
\end{array}$ & $\begin{array}{l}\text { n.s. } \\
\text { Réf. } \\
\text { n.s. } \\
0,29 \\
0,85 \\
1,14\end{array}$ & $\begin{array}{l}\text { n.s. } \\
\text { Réf. } \\
\text { n.s. } \\
0,18 \\
0,58 \\
1,22 \\
\end{array}$ \\
\hline Période & $\begin{array}{l}1968-1975 \\
1975-1982 \\
1982-1990\end{array}$ & $\begin{array}{l}\text { III } \\
\text { Réf. } \\
\text { III }\end{array}$ & $\begin{array}{l}\text { III } \\
\text { Réf. } \\
\text { III }\end{array}$ & $\begin{array}{l}\text { III } \\
\text { Réf. } \\
\text { III }\end{array}$ & $\begin{array}{l}\text { n.s. } \\
\text { Réf. } \\
0,15\end{array}$ & $\begin{array}{l}\text { III } \\
\text { Réf. } \\
\text { III }\end{array}$ & $\begin{array}{c}\text { III } \\
\text { Réf. } \\
\text { III }\end{array}$ & $\begin{array}{c}\text { III } \\
\text { Réf. } \\
\text { III }\end{array}$ & $\begin{array}{r}-0,12 \\
\text { Réf. } \\
-0,33\end{array}$ & $\begin{array}{l}\text { III } \\
\text { Réf. } \\
\text { III }\end{array}$ & $\begin{array}{l}\text { III } \\
\text { Réf. } \\
\text { III }\end{array}$ & $\begin{array}{l}\text { III } \\
\text { Réf. } \\
\text { III }\end{array}$ & $\begin{array}{r}-1,15 \\
\text { Réf. } \\
0,38\end{array}$ \\
\hline Diplôme & $\begin{array}{l}\text { Sans diplôme, non déclaré } \\
\text { CEP } \\
\text { CAP, BEP ou équivalent } \\
\text { Supérieur au CAP-BEP }\end{array}$ & $\begin{array}{r}-1,22 \\
-0,28 \\
\text { Réf. } \\
1,05\end{array}$ & $\begin{array}{r}-1,20 \\
-0,40 \\
\text { Réf. } \\
1,05\end{array}$ & $\begin{array}{r}-0,91 \\
-0,49 \\
\text { Réf. } \\
1,09\end{array}$ & $\begin{array}{r}-1,12 \\
-0,39 \\
\text { Réf. } \\
1,04\end{array}$ & $\begin{array}{r}-0,77 \\
-0,21 \\
\text { Réf. } \\
0,16\end{array}$ & $\begin{array}{r}-0,80 \\
-0,23 \\
\text { Réf. } \\
0,24\end{array}$ & $\begin{array}{r}-0,55 \\
-0,27 \\
\text { Réf. } \\
0,40\end{array}$ & $\begin{array}{r}-0,73 \\
-0,23 \\
\text { Réf. } \\
0,28\end{array}$ & $\begin{array}{l}0,45 \\
0,23 \\
\text { Réf. } \\
0,29\end{array}$ & $\begin{array}{l}0,48 \\
0,24 \\
\text { Réf. } \\
\text { n.s. }\end{array}$ & $\begin{array}{r}0,50 \\
0,27 \\
\text { Réf. } \\
-0,16\end{array}$ & $\begin{array}{l}0,48 \\
0,25 \\
\text { Réf. } \\
\text { n.s. }\end{array}$ \\
\hline $\begin{array}{l}\text { Situation } \\
\text { matrimoniale }\end{array}$ & $\begin{array}{l}\text { Célibataire } \\
\text { Marié } \\
\text { Veuf, divorcé } \\
\end{array}$ & $\begin{array}{r}-0,41 \\
\text { Réf. } \\
-0,37\end{array}$ & $\begin{array}{l}-0,34 \\
\text { Réf. } \\
\text { n.s. }\end{array}$ & $\begin{array}{r}-0,31 \\
\text { Réf. } \\
-0,27 \\
\end{array}$ & $\begin{array}{r}-0,35 \\
\text { Réf. } \\
-0,23 \\
\end{array}$ & $\begin{array}{l}-0,40 \\
\text { Rét. } \\
\text { n.s. }\end{array}$ & $\begin{array}{l}-0,41 \\
\text { Réf. } \\
\text { n.s. }\end{array}$ & $\begin{array}{c}-0,22 \\
\text { Réf. } \\
\text { n.s. }\end{array}$ & $\begin{array}{l}-0,32 \\
\text { Réf. } \\
\text { n.s. }\end{array}$ & $\begin{array}{c}0,64 \\
\text { Réf. } \\
1,09\end{array}$ & $\begin{array}{l}0,66 \\
\text { Réf. } \\
0,79\end{array}$ & $\begin{array}{l}0,60 \\
\text { Réf. } \\
0,87\end{array}$ & $\begin{array}{l}0,64 \\
\text { Réf. } \\
0,89\end{array}$ \\
\hline Nationalité & $\begin{array}{l}\text { Français de naissance } \\
\text { Français par acquisition } \\
\text { Étranger }\end{array}$ & $\begin{array}{r}\text { Réf. } \\
\text { n.s. } \\
-0,63 \\
\end{array}$ & $\begin{array}{r}\begin{array}{r}\text { Réf. } \\
\text { n.S. } \\
-0,55\end{array} \\
\end{array}$ & $\begin{array}{r}\text { Réf. } \\
-0,28 \\
-0,68 \\
\end{array}$ & $\begin{array}{r}\text { Réf. } \\
-0,12 \\
-0,63 \\
\end{array}$ & $\begin{array}{r}\begin{array}{r}\text { Réf. } \\
\text { n.s. } \\
-0,24\end{array} \\
\end{array}$ & $\begin{array}{r}\text { Réf. } \\
\text { n.s. } \\
-0,28 \\
\end{array}$ & $\begin{array}{r}\text { Réf. } \\
\text { n.s. } \\
0,46\end{array}$ & $\begin{array}{l}\text { Réf. } \\
\text { n.s. } \\
\text { n.s. } \\
\end{array}$ & $\begin{array}{l}\text { Réf. } \\
\text { n.s. } \\
\text { n.s. }\end{array}$ & $\begin{array}{r}\text { Réf. } \\
\text { n.s. } \\
0,23 \\
\end{array}$ & $\begin{array}{r}\text { Réf. } \\
\text { n.s. } \\
0,18 \\
\end{array}$ & $\begin{array}{c}\text { Réf. } \\
\text { n.s. } \\
0,20 \\
\end{array}$ \\
\hline $\begin{array}{l}\text { Catégories } \\
\text { socioprofessionnelles }\end{array}$ & $\begin{array}{l}\text { Employé } \\
\text { Ouvrier qualifié de type industriel } \\
\text { Ouvrier qualifié de type artisanal } \\
\text { Chauffeur } \\
\text { Ouvrier des transports et manutention } \\
\text { Ouvrier non qualifie industriel } \\
\text { Ouvrier non qualifié artisanal } \\
\end{array}$ & $\begin{array}{r}0,23 \\
\text { Réf. } \\
-0,35 \\
-0,75 \\
\text { n.s. } \\
-0,60 \\
-0,84 \\
\end{array}$ & $\begin{array}{r}\text { n.s. } \\
\text { Réf. } \\
-0,43 \\
-1,06 \\
-0,41 \\
-0,80 \\
-1,10 \\
\end{array}$ & $\begin{array}{r}0,32 \\
\text { Réf. } \\
-0,33 \\
-0,95 \\
-0,29 \\
-0,64 \\
-0,78 \\
\end{array}$ & $\begin{array}{r}\text { n.s. } \\
\text { Réf. } \\
-0,37 \\
-0,94 \\
-0,30 \\
-0,69 \\
-0,90 \\
\end{array}$ & $\begin{array}{r}0,38 \\
\text { Réf. } \\
0,88 \\
0,44 \\
\text { n.s. } \\
\text { n.s. } \\
0,48 \\
\end{array}$ & $\begin{array}{r}\text { n.s. } \\
\text { Réf. } \\
0,75 \\
0,34 \\
-0,43 \\
\text { n.s. } \\
0,37 \\
\end{array}$ & $\begin{array}{r}-0,21 \\
\text { Réf. } \\
0,62 \\
0,43 \\
\text { n.s. } \\
-0,30 \\
0,29 \\
\end{array}$ & $\begin{array}{r}0,02 \\
\text { Réf. } \\
0,74 \\
0,41 \\
\text { n.s. } \\
-0,18 \\
0,37 \\
\end{array}$ & $\begin{array}{r}\text { n.s. } \\
\text { Réf. } \\
0,69 \\
\text { n.s. } \\
\text { n.s. } \\
0,39 \\
0,62 \\
\end{array}$ & $\begin{array}{r}-0,35 \\
\text { Réf. } \\
0,15 \\
0,13 \\
0,35 \\
0,30 \\
0,29 \\
\end{array}$ & $\begin{array}{r}-0,17 \\
\text { Réf. } \\
\text { n.s. } \\
0,19 \\
0,51 \\
0,40 \\
0,48 \\
\end{array}$ & $\begin{array}{r}-0,25 \\
\text { Réf. } \\
0,15 \\
0,14 \\
0,38 \\
0,34 \\
0,36 \\
\end{array}$ \\
\hline $\begin{array}{l}\text { Tranche } \\
\text { d'unité urbaine }\end{array}$ & $\begin{array}{l}\text { Communes rurales } \\
\text { UU } 2000 \text { à } 99999 \text { habitants } \\
\text { UU } 100000 \text { à } 1999999 \text { habitants } \\
\text { Agglomération parisienne }\end{array}$ & $\begin{array}{r}-0,38 \\
-0,18 \\
\text { Réf. } \\
0,14 \\
\end{array}$ & $\begin{array}{r}-0,30 \\
-0,17 \\
\text { Réf. } \\
0,19 \\
\end{array}$ & $\begin{array}{r}-0,25 \\
-0,12 \\
\text { Réf. } \\
0,30 \\
\end{array}$ & $\begin{array}{r}-0,30 \\
-0,16 \\
\text { Réf. } \\
0,22 \\
\end{array}$ & $\begin{array}{r}0,30 \\
\text { n.s. } \\
\text { Réf. } \\
-0,19 \\
\end{array}$ & $\begin{array}{r}0,31 \\
0,17 \\
\text { Réf. } \\
-0,10 \\
\end{array}$ & $\begin{array}{r}0,19 \\
\text { n.s. } \\
\text { Réf. } \\
0,06 \\
\end{array}$ & $\begin{array}{r}0,28 \\
0,11 \\
\text { Péf. } \\
-0,06 \\
\end{array}$ & $\begin{array}{r}-0,47 \\
-0,28 \\
\text { Rét. } \\
\text { n.s. } \\
\end{array}$ & $\begin{array}{r}-0,56 \\
-0,26 \\
\text { Réf. } \\
-0,19 \\
\end{array}$ & $\begin{array}{r}-0,51 \\
-0,27 \\
\text { Réf. } \\
-0,29 \\
\end{array}$ & $\begin{array}{r}-0,53 \\
-0,27 \\
\text { Réf. } \\
-0,19 \\
\end{array}$ \\
\hline $\begin{array}{l}\text { Mobilité } \\
\text { sectorielle et } \\
\text { géographique (1) }\end{array}$ & $\begin{array}{l}\text { Même établissement } \\
\text { Établissement différent, même secteur et départ. } \\
\text { Même secteur, département différent } \\
\text { Secteur différent, même département } \\
\text { Secteur et département différents }\end{array}$ & $\begin{array}{c}\text { Réf. } \\
\text { n.s. } \\
0,29 \\
\text { n.s. } \\
0,56\end{array}$ & $\begin{array}{c}\text { Réf. } \\
\text { n.s. } \\
0,38 \\
\text { n.s. } \\
0,35\end{array}$ & $\begin{array}{l}\text { Réf. } \\
\text { n.s. } \\
0,51 \\
0,12 \\
0,59\end{array}$ & $\begin{array}{l}\text { Réf. } \\
\text { n.s. } \\
0,40 \\
0,07 \\
0,51\end{array}$ & $\begin{array}{l}\text { Réf. } \\
1,60 \\
1,56 \\
1,02 \\
1,33\end{array}$ & $\begin{array}{l}\text { Réf. } \\
2,14 \\
2,07 \\
1,77 \\
1,91\end{array}$ & $\begin{array}{l}\text { Réf. } \\
1,09 \\
1,31 \\
1,25 \\
1,65\end{array}$ & $\begin{array}{l}\text { Réf. } \\
1,63 \\
1,70 \\
1,41 \\
1,67\end{array}$ & $\begin{array}{l}\text { Réf. } \\
\text { III } \\
\text { III } \\
\text { III } \\
0,37\end{array}$ & $\begin{array}{c}\text { Réf. } \\
\text { III } \\
\text { III } \\
\text { III } \\
0,34\end{array}$ & $\begin{array}{c}\text { Réf. } \\
\text { III } \\
\text { III } \\
\text { III } \\
0,54\end{array}$ & $\begin{array}{c}\text { Réf. } \\
\text { III } \\
\text { III } \\
\text { III } \\
0,43\end{array}$ \\
\hline Secteur d'activité (2) & $\begin{array}{l}\text { Production et distribution d'éléctricité et de gaz } \\
\text { Sidérurgie } \\
\text { Chimie } \\
\text { Construction automobile } \\
\text { Boulangerie, patisserie } \\
\text { Textile, habillement, cuir } \\
\text { Papier et carton } \\
\text { Bâtiment et travaux publics } \\
\text { Commerce de détail, hôtel } \\
\text { Réparation automobiles } \\
\text { Transports ferroviaires } \\
\text { Autres activités industrielles } \\
\text { Autre s activités tertiaires }\end{array}$ & $\begin{array}{r}0,42 \\
\text { n.s. } \\
0,41 \\
0,30 \\
-1,30 \\
\text { n.s. } \\
0,31 \\
-0,28 \\
\text { n.s. } \\
\text { n.s. } \\
-0,59 \\
\text { Rét. } \\
-0,17\end{array}$ & $\begin{array}{r}0,69 \\
\text { n.s. } \\
\text { n.s. } \\
\text { n.s. } \\
-0,63 \\
\text { n.s. } \\
\text { n.s. } \\
-0,33 \\
\text { n.s. } \\
\text { n.s. } \\
\text { n.s. } \\
\text { Réf. } \\
-0,33\end{array}$ & $\begin{array}{r}0,94 \\
0,30 \\
0,33 \\
-0,31 \\
-0,78 \\
\text { n.s. } \\
\text { n.s. } \\
-0,45 \\
\text { n.s. } \\
\text { n.s. } \\
\text { n.s. } \\
\text { Rét. } \\
-0,23\end{array}$ & $\begin{array}{r}0,69 \\
\text { n.s. } \\
0,24 \\
\text { n.s. } \\
-0,89 \\
\text { n.s. } \\
\text { n.s. } \\
-0,34 \\
\text { n.s. } \\
\text { n.s. } \\
-0,25 \\
\text { Réf. } \\
-0,24\end{array}$ & $\begin{array}{r}-2,66 \\
-1,28 \\
\text { n.s. } \\
-0,51 \\
1,00 \\
\text { n.s. } \\
\text { n.s. } \\
0,51 \\
1,20 \\
0,64 \\
-1,84 \\
\text { Rét. } \\
\text { n.s. }\end{array}$ & $\begin{array}{r}-1,75 \\
\text { n.s. } \\
\text { n.s. } \\
\text { n.s. } \\
0,96 \\
\text { n.s. } \\
\text { n.s. } \\
0,59 \\
1,05 \\
0,43 \\
-1,27 \\
\text { Réf. } \\
\text { n.s. }\end{array}$ & $\begin{array}{r}-1,80 \\
\text { n.s. } \\
\text { n.s. } \\
\text { n.s. } \\
1,19 \\
\text { n.s. } \\
\text { n.s. } \\
0,47 \\
0,99 \\
0,38 \\
-1,43 \\
\text { Réf. } \\
-0,18\end{array}$ & $\begin{array}{r}-2,15 \\
-0,46 \\
-0,49 \\
-0,24 \\
1,05 \\
\text { n.s. } \\
\text { n.s. } \\
0,53 \\
1,08 \\
0,48 \\
-1,50 \\
\text { Réf. } \\
-0,13\end{array}$ & & $\begin{array}{r}-2,06 \\
-0,43 \\
\text { n.s. } \\
-0,45 \\
\text { n.s. } \\
\text { n.s. } \\
\text { n.s. } \\
0,28 \\
0,24 \\
0,40 \\
-1,46 \\
\text { Réf. } \\
-0,26 \\
\end{array}$ & $\begin{array}{r}-2,06 \\
\text { n.s. } \\
-0,67 \\
-0,45 \\
\text { n.s. } \\
0,25 \\
-0,76 \\
0,15 \\
0,43 \\
\text { n.s. } \\
-1,50 \\
\text { Réf. } \\
-0,30 \\
\end{array}$ & $\begin{array}{r}-2,19 \\
-0,48 \\
-0,26 \\
-0,38 \\
0,26 \\
0,19 \\
\text { n.s. } \\
0,24 \\
0,35 \\
-0,26 \\
-1,40 \\
\text { Réf. } \\
-0,28\end{array}$ \\
\hline
\end{tabular}


Annexe II (fin) - DEVENIR DES OUVRIERS ET DES EMPLOYÉS

Coefficients de régression avec prise en compte des catégories socioprofessionnelles, de la mobilité et des secteurs détaillés

A-2 Femmes

\begin{tabular}{|c|c|c|c|c|c|c|c|c|c|c|c|c|c|c|c|c|c|}
\hline & & \multicolumn{16}{|c|}{ Situation en fin de période intercensitaire } \\
\hline & & \multicolumn{4}{|c|}{ Cadre ou profession intermédiaire } & \multicolumn{4}{|c|}{ À son compte } & \multicolumn{4}{|c|}{ Chomâge } & \multicolumn{4}{|c|}{ Au foyer } \\
\hline & & $68-75$ & $75-82$ & $82-90$ & $\begin{array}{c}3 \\
\text { périodes }\end{array}$ & $68-75$ & $75-82$ & $82-90$ & $\begin{array}{c}3 \\
\text { périodes }\end{array}$ & $68-75$ & 75-82 & 82-90 & $\begin{array}{c}3 \\
\text { périodes }\end{array}$ & $68-75$ & 75-82 & $82-90$ & $\begin{array}{c}3 \\
\text { périodes }\end{array}$ \\
\hline \multicolumn{2}{|c|}{ Situation de référence } & $-2,51$ & $-2,38$ & $-2,44$ & $-2,56$ & $-4,45$ & $-5,97$ & $-5,60$ & \begin{tabular}{|l|l|}
$-5,28$ \\
\end{tabular} & $-3,69$ & $-3,24$ & $-2,62$ & $-3,04$ & $-1,31$ & $-1,70$ & $-2,07$ & $-1,65$ \\
\hline Âge & $\begin{array}{l}16 \text { à } 22 \text { ans } \\
23 \text { à } 29 \text { ans } \\
30 \text { à } 36 \text { ans } \\
37 \text { à } 43 \text { ans } \\
44 \text { à } 50 \text { ans } \\
51 \text { à } 57 \text { ans }\end{array}$ & $\begin{array}{c}-0,42 \\
\text { Réf. } \\
\text { n.s. } \\
\text { n.s. } \\
-0,38 \\
-0,38 \\
\end{array}$ & $\begin{array}{l}-0,48 \\
\text { Réf. } \\
\text { n.s. } \\
\text { n.s. } \\
\text { n.s. } \\
\text { n.s. } \\
\end{array}$ & $\begin{array}{c}-0,23 \\
\text { Réf. } \\
0,34 \\
0,38 \\
\text { n.s. } \\
-1,16 \\
\end{array}$ & $\begin{array}{c}-0,39 \\
\text { Réf. } \\
0,19 \\
0,14 \\
\text { n.s. } \\
-0,13 \\
\end{array}$ & $\begin{array}{l}-0,54 \\
\text { Réf. } \\
-0,46 \\
-0,54 \\
-0,92 \\
-1,33 \\
\end{array}$ & $\begin{array}{l}\text { n.s. } \\
\text { Réf. } \\
0,30 \\
\text { n.s. } \\
\text { n.s. } \\
\text { n.s. } \\
\end{array}$ & $\begin{array}{c}\text { n.s. } \\
\text { Réf. } \\
0,41 \\
0,72 \\
\text { n.s. } \\
-1,15 \\
\end{array}$ & $\begin{array}{c}-0,21 \\
\text { Réf. } \\
\text { n.s. } \\
\text { n.s. } \\
-0,34 \\
-0,44 \\
\end{array}$ & $\begin{array}{c}0,30 \\
\text { Réf. } \\
-0,37 \\
-0,52 \\
\text { n.s. } \\
0,31 \\
\end{array}$ & $\begin{array}{c}0,27 \\
\text { Réf. } \\
-0,24 \\
-0,40 \\
0,19 \\
0,79 \\
\end{array}$ & $\begin{array}{r}0,14 \\
\text { Réf. } \\
-0,20 \\
-0,17 \\
0,20 \\
-0,85 \\
\end{array}$ & $\begin{array}{r}0,25 \\
\text { Réf. } \\
-0,24 \\
-0,29 \\
0,25 \\
0,59 \\
\end{array}$ & $\begin{array}{l}0,23 \\
\text { Réf. } \\
-0,79 \\
-1,28 \\
-1,17 \\
-0,95 \\
\end{array}$ & $\begin{array}{l}0,35 \\
\text { Réf. } \\
-0,70 \\
-0,90 \\
-0,57 \\
0,14 \\
\end{array}$ & $\begin{array}{l}0,22 \\
\text { Réf. } \\
-0,71 \\
-0,74 \\
-0,19 \\
-0,32 \\
\end{array}$ & $\begin{array}{l}0,34 \\
\text { Réff. } \\
-0,73 \\
-0,95 \\
-0,55 \\
\text { n.s. }\end{array}$ \\
\hline Période & $\begin{array}{l}1968-1975 \\
1975-1982 \\
1982-1990\end{array}$ & $\begin{array}{l}\text { III } \\
\text { Réf. } \\
\text { III }\end{array}$ & $\begin{array}{l}\text { III } \\
\text { Réf. } \\
\text { III }\end{array}$ & III & $\begin{array}{l}-0,09 \\
\text { Réf. } \\
0,48 \\
\end{array}$ & $\begin{array}{l}\text { III } \\
\text { Réf. } \\
\text { III }\end{array}$ & $\begin{array}{l}\text { III } \\
\text { Réf. } \\
\text { III }\end{array}$ & $\begin{array}{l}\text { III } \\
\text { Réf. } \\
\text { III }\end{array}$ & $\begin{array}{r}0,15 \\
\text { Réf. } \\
-0,08 \\
\end{array}$ & $\begin{array}{l}\text { III } \\
\text { Réf. } \\
\text { III }\end{array}$ & $\begin{array}{l}\text { III } \\
\text { Réf. } \\
\text { III }\end{array}$ & $\begin{array}{l}\text { III } \\
\text { Réf. } \\
\text { III }\end{array}$ & $\begin{array}{l}-0,99 \\
\text { Réf. } \\
0,49 \\
\end{array}$ & $\begin{array}{l}\text { III } \\
\text { Réf. } \\
\text { III }\end{array}$ & $\begin{array}{l}\text { ill } \\
\text { Réf. } \\
\text { ill }\end{array}$ & $\begin{array}{c}\text { III } \\
\text { Réf. } \\
\text { III }\end{array}$ & $\begin{array}{l}0,18 \\
\text { Réf. } \\
-0,28\end{array}$ \\
\hline Diplôme & $\begin{array}{l}\text { Sans diplôme, non déclaré } \\
\text { CEP } \\
\text { CAP, BEP ou équivalent } \\
\text { Supérieur au CAP-BEP }\end{array}$ & $\begin{array}{l}-1,40 \\
-0,33 \\
\text { Réf. } \\
0,95 \\
\end{array}$ & $\begin{array}{l}-1,10 \\
-0,35 \\
\text { Réf. } \\
0,81 \\
\end{array}$ & $\begin{array}{l}-1,02 \\
-0,44 \\
\text { Réf. } \\
1,00 \\
\end{array}$ & $\begin{array}{l}-1,04 \\
-0,37 \\
\text { Réf. } \\
0,92 \\
\end{array}$ & $\begin{array}{l}-1,06 \\
-0,44 \\
\text { Réf. } \\
0,64 \\
\end{array}$ & $\begin{array}{l}-0,59 \\
-0,03 \\
\text { Réf. } \\
0,61\end{array}$ & $\begin{array}{l}-1,13 \\
-0,62 \\
\text { Réf. } \\
\text { n.s. } \\
\end{array}$ & $\begin{array}{l}-0,99 \\
-0,40 \\
\text { Réf. } \\
0,38 \\
\end{array}$ & $\begin{array}{l}0,36 \\
\text { n.s. } \\
\text { Réf. } \\
\text { n.s. }\end{array}$ & $\begin{array}{l}\text { n.s. } \\
\text { n.s. } \\
\text { Réf. } \\
-0,16 \\
\end{array}$ & $\begin{array}{l}\text { n.s. } \\
\text { n.s. } \\
\text { Réf. } \\
-0,30\end{array}$ & $\begin{array}{l}0,19 \\
0,08 \\
\text { Réf. } \\
-0,25 \\
\end{array}$ & $\begin{array}{l}0,47 \\
0,23 \\
\text { Réf. } \\
-0,12 \\
\end{array}$ & $\begin{array}{l}0,41 \\
0,15 \\
\text { Péf. } \\
\text { n.s. }\end{array}$ & $\begin{array}{l}\text { n.s. } \\
\text { n.s. } \\
\text { Réf. } \\
-0,11 \\
\end{array}$ & $\begin{array}{r}0,40 \\
0,19 \\
\text { Réf. } \\
-0,15\end{array}$ \\
\hline $\begin{array}{l}\text { Situation } \\
\text { matrimoniale }\end{array}$ & $\begin{array}{l}\text { Célibataire } \\
\text { Marié } \\
\text { Veuf, divorcé } \\
\end{array}$ & $\begin{array}{l}0,18 \\
\text { Réf. } \\
\text { n.s. }\end{array}$ & $\begin{array}{l}0,11 \\
\text { Réf. } \\
\text { n.s. }\end{array}$ & $\begin{array}{l}0,13 \\
\text { Réf. } \\
\text { n.s. }\end{array}$ & $\begin{array}{l}0,16 \\
\text { Réf. } \\
\text { n.s. }\end{array}$ & $\begin{array}{l}-0,67 \\
\text { Réf. } \\
\text { n.s. }\end{array}$ & $\begin{array}{l}\text { n.s. } \\
\text { Réf. } \\
\text { n.s. }\end{array}$ & $\begin{array}{l}-0,21 \\
\text { Réf. } \\
\text { n.s. }\end{array}$ & $\begin{array}{l}-0,41 \\
\text { Réf. } \\
\text { n.s. }\end{array}$ & $\begin{array}{l}-0,01 \\
\text { Réf. } \\
0,02 \\
\end{array}$ & $\begin{array}{l}0,14 \\
\text { Réf. } \\
\text { n.s. }\end{array}$ & $\begin{array}{l}0,15 \\
\text { Réf. } \\
0,14\end{array}$ & $\begin{array}{l}0,09 \\
\text { Réf. } \\
\text { n.s. }\end{array}$ & $\begin{array}{l}-0,36 \\
\text { Réf. } \\
-0,46\end{array}$ & $\begin{array}{l}-0,32 \\
\text { Pét. } \\
-0,35 \\
\end{array}$ & $\begin{array}{c}-0,36 \\
\text { Réf. } \\
-0,38\end{array}$ & $\begin{array}{c}-0,35 \\
\text { Rë́f. } \\
-0,42 \\
\end{array}$ \\
\hline $\begin{array}{l}\text { Catégorie } \\
\text { socio- professionnelle }\end{array}$ & $\begin{array}{l}\text { Emp. de la Fonction publique } \\
\text { Emp. administr. d'entrep. } \\
\text { Employée de commerce } \\
\text { Pers. de service aux particuliers } \\
\text { Ouvrière }\end{array}$ & $\begin{array}{l}-0,19 \\
\text { Réf. } \\
\text { n.s. } \\
-1,15 \\
-0,43 \\
\end{array}$ & $\begin{array}{l}-0,39 \\
\text { Réf. } \\
-0,39 \\
-1,14 \\
-0,79 \\
\end{array}$ & $\begin{array}{l}-0,48 \\
\text { Réf. } \\
-0,50 \\
-1,54 \\
-1,13 \\
\end{array}$ & $\begin{array}{l}-0,42 \\
\text { Réf. } \\
-0,35 \\
-1,34 \\
-0,84 \\
\end{array}$ & $\begin{array}{l}-0,84 \\
\text { Réf. } \\
1,14 \\
1,46 \\
0,96 \\
\end{array}$ & $\begin{array}{l}-0,72 \\
\text { Réf. } \\
1,23 \\
1,12 \\
0,43 \\
\end{array}$ & $\begin{array}{l}-0,91 \\
\text { Réf. } \\
0,93 \\
1,29 \\
\text { n.s. }\end{array}$ & $\begin{array}{l}-0,82 \\
\text { Réf. } \\
1,11 \\
1,30 \\
0,60 \\
\end{array}$ & $\begin{array}{l}-0,96 \\
\text { Réf. } \\
\text { n.s. } \\
\text { n.s. } \\
\text { n.s. } \\
\end{array}$ & $\begin{array}{l}-0,93 \\
\text { Réf. } \\
0,40 \\
0,25 \\
0,39 \\
\end{array}$ & $\begin{aligned}-1,20 \\
\text { Réf. } \\
0,28 \\
0,22 \\
0,26 \\
\end{aligned}$ & $\begin{array}{l}-1,13 \\
\text { Réf. } \\
0,30 \\
0,26 \\
0,33 \\
\end{array}$ & $\begin{array}{l}-0,24 \\
\text { Réf. } \\
0,53 \\
0,80 \\
0,50 \\
\end{array}$ & $\begin{array}{l}-0,40 \\
\text { Péf. } \\
0,33 \\
0,63 \\
0,42 \\
\end{array}$ & $\begin{array}{l}-0,43 \\
\text { Réf. } \\
0,44 \\
0,65 \\
0,46 \\
\end{array}$ & $\begin{array}{l}-0,40 \\
\text { Réf. } \\
0,42 \\
0,70 \\
0,44 \\
\end{array}$ \\
\hline $\begin{array}{l}\text { Tranche } \\
\text { d'unité urbaine }\end{array}$ & $\begin{array}{l}\text { Communes rurales } \\
\text { UU } 2000 \text { à } 99999 \text { habitants } \\
\text { UU } 100000 \text { à } 1999999 \mathrm{~h} \text {. } \\
\text { Agglomération parisienne }\end{array}$ & $\begin{array}{c}\text { n.s. } \\
-0,18 \\
\text { Réf. } \\
0,18 \\
\end{array}$ & $\begin{array}{l}-0,26 \\
-0,10 \\
\text { Réf. } \\
0,36 \\
\end{array}$ & $\begin{array}{l}\text { n.s. } \\
\text { n.s. } \\
\text { Réf. } \\
0,64 \\
\end{array}$ & $\begin{array}{l}-0,15 \\
\text { n.s. } \\
\text { Réf. } \\
0,45 \\
\end{array}$ & $\begin{array}{l}\text { n.s. } \\
\text { n.s. } \\
\text { Réf. } \\
-0,31 \\
\end{array}$ & $\begin{array}{c}\text { n.s. } \\
\text { n.s. } \\
\text { Réf. } \\
-0,35 \\
\end{array}$ & $\begin{array}{l}\text { n.s. } \\
\text { n.s. } \\
\text { Réf. } \\
\text { n.s. }\end{array}$ & $\begin{array}{l}\text { n.s. } \\
\text { n.s. } \\
\text { Réf. } \\
-0,32 \\
\end{array}$ & $\begin{array}{l}-0,58 \\
-0,20 \\
\text { Réf. } \\
0,20 \\
\end{array}$ & $\begin{array}{l}-0,31 \\
-0,18 \\
\text { Réf. } \\
-0,35 \\
\end{array}$ & $\begin{array}{l}-0,11 \\
\text { n.s. } \\
\text { Réf. } \\
-0,24 \\
\end{array}$ & $\begin{array}{c}-0,30 \\
-0,15 \\
\text { Réf. } \\
-0,39 \\
\end{array}$ & $\begin{array}{l}\text { n.s. } \\
\text { n.s. } \\
\text { Réf. } \\
-0,53 \\
\end{array}$ & $\begin{array}{c}-0,12 \\
-0,19 \\
\text { Réf. } \\
-0,54 \\
\end{array}$ & $\begin{array}{l}\text { n.s. } \\
\text { n.s. } \\
\text { Réf. } \\
-0,36 \\
\end{array}$ & $\begin{array}{l}-0,07 \\
-0,13 \\
\text { Réf. } \\
-0,55 \\
\end{array}$ \\
\hline $\begin{array}{l}\text { Mobilité } \\
\text { sectorielle et } \\
\text { géographique (1) }\end{array}$ & $\begin{array}{l}\text { Même établissement } \\
\text { Ét.différent, même sect. et dép. } \\
\text { Même sect., dép. différent } \\
\text { Sect. différent, même dép. } \\
\text { Sect. et département différents }\end{array}$ & $\begin{array}{l}\text { Réf. } \\
\text { n.s. } \\
0,45 \\
\text { n.s. } \\
0,29 \\
\end{array}$ & $\begin{array}{l}\text { Röf. } \\
\text { n.s. } \\
0,49 \\
0,17 \\
0,42 \\
\end{array}$ & $\begin{array}{l}\text { Réf. } \\
0,14 \\
0,41 \\
-0,40 \\
-0,22 \\
\end{array}$ & $\begin{array}{l}\text { Réf. } \\
0,07 \\
0,52 \\
0,10 \\
0,44 \\
\end{array}$ & $\begin{array}{l}\text { Réf. } \\
1,28 \\
1,34 \\
1,18 \\
1,59 \\
\end{array}$ & $\begin{array}{l}\text { Réf. } \\
2,01 \\
2,46 \\
2,48 \\
2,61 \\
\end{array}$ & $\begin{array}{l}\text { Réf. } \\
1,16 \\
1,40 \\
1,03 \\
1,12 \\
\end{array}$ & $\begin{array}{l}\text { Réf. } \\
1,38 \\
1,76 \\
1,79 \\
1,97\end{array}$ & $\begin{array}{l}\text { Réf. } \\
\text { III } \\
I I \prime \\
I I \prime \\
0,94\end{array}$ & $\begin{array}{l}\text { Réf. } \\
\text { III } \\
I I I \\
I I I \\
1,14 \\
\end{array}$ & $\begin{array}{c}\text { Réf. } \\
\text { III } \\
\text { III } \\
\text { III } \\
0,33 \\
\end{array}$ & $\begin{array}{l}\text { Réf. } \\
\text { III } \\
I I I \\
I I I \\
1,11 \\
\end{array}$ & $\begin{array}{l}\text { Réf. } \\
\text { III } \\
I I I \\
I I I \\
0,78\end{array}$ & $\begin{array}{l}\text { Réf. } \\
! I I \\
! I \prime \\
! I ! \\
1,06\end{array}$ & $\begin{array}{l}\text { Réf. } \\
I I I \\
I I I \\
I I I \\
0,39\end{array}$ & $\begin{array}{l}\text { Réf. } \\
\text { III } \\
I I I \\
I I I \\
1,00\end{array}$ \\
\hline Secteur d'activité & $\begin{array}{l}\text { Boulangerie, patisserie } \\
\text { Bâtiment } \\
\text { Autres act. agricoles et industr. } \\
\text { Commerce } \\
\text { Réparation, com. automobiles } \\
\text { Hôtel, cafés, restaurants } \\
\text { Poste, télécom.munication } \\
\text { Assurances } \\
\text { Organismes financiers } \\
\text { Enseignement } \\
\text { Santé } \\
\text { Autres activités tertiaires } \\
\text { Indéterminé }\end{array}$ & $\begin{array}{l}-2,16 \\
\text { n.s. } \\
\text { n.s. } \\
\text { n.s. } \\
\text { n.s. } \\
\text { n.s. } \\
\text { n.s. } \\
0,37 \\
-0,33 \\
\text { n.s. } \\
\text { n.s. } \\
\text { Rét. } \\
\text { n.s. }\end{array}$ & $\begin{array}{l}-1,47 \\
\text { n.s. } \\
\text { n.s. } \\
\text { n.s. } \\
\text { n.s. } \\
\text { n.s. } \\
0,72 \\
0,42 \\
-0,64 \\
-0,42 \\
-0,21 \\
\text { Réf. } \\
\text { n.s. }\end{array}$ & $\begin{array}{c}\text { n.s. } \\
\text { n.s. } \\
\text { n.s. } \\
\text { n.s. } \\
-0,57 \\
\text { n.s. } \\
0,42 \\
0,40 \\
-0,24 \\
\text { n.s. } \\
-0,54 \\
\text { Réf. } \\
\text { n.s. }\end{array}$ & $\begin{array}{c}-0,94 \\
\text { n.s. } \\
\text { n.s. } \\
-0,18 \\
-0,39 \\
\text { n.s. } \\
0,49 \\
0,36 \\
-0,36 \\
\text { n.s. } \\
-0,39 \\
\text { Réf. } \\
\text { n.s. }\end{array}$ & $\begin{array}{c}0,90 \\
\text { n.s. } \\
-0,68 \\
0,70 \\
0,97 \\
0,85 \\
\text { n.s. } \\
\text { n.s. } \\
-1,59 \\
\text { n.s. } \\
\text { n.s. } \\
\text { Réf. } \\
\text { n.s. }\end{array}$ & $\begin{array}{l}\text { n.s. } \\
\text { n.s. } \\
\text { n.s. } \\
\text { n.s. } \\
\text { n.s. } \\
\text { n.s. } \\
\text { n.s. } \\
\text { n.s. } \\
\text { n.s. } \\
\text { n.s. } \\
\text { n.s. } \\
\text { Réf. } \\
\text { n.s. }\end{array}$ & $\begin{array}{l}\text { n.s. } \\
\text { n.s. } \\
\text { n.s. } \\
0,70 \\
0,88 \\
0,58 \\
\text { n.s. } \\
\text { n.s. } \\
\text { n.s. } \\
\text { n.s. } \\
\text { n.s. } \\
\text { Réf. } \\
\text { n.s. }\end{array}$ & $\begin{array}{l}\text { n.s. } \\
\text { n.s. } \\
\text { n.s. } \\
0,58 \\
0,56 \\
0,58 \\
\text { n.s. } \\
-0,44 \\
-0,79 \\
-0,54 \\
\text { n.s. } \\
\text { Réf. } \\
\text { n.s. }\end{array}$ & $\begin{array}{l}\text { n.s. } \\
\text { n.s. } \\
0,29 \\
\text { n.s. } \\
\text { n.s. } \\
\text { n.s. } \\
\text { n.s. } \\
\text { n.s. } \\
-0,79 \\
\text { n.s. } \\
\text { n.s. } \\
\text { Réf. } \\
\text { n.s. }\end{array}$ & $\begin{array}{c}0,48 \\
0,83 \\
0,63 \\
0,42 \\
0,95 \\
0,59 \\
\text { n.s. } \\
-0,25 \\
-1,00 . \\
\text { n.s. } \\
0,42 \\
\text { Réf. } \\
0,70 \\
\end{array}$ & $\begin{array}{c}0,28 \\
0,48 \\
0,40 \\
0,46 \\
0,65 \\
0,43 \\
-0,74 \\
-0,25 \\
-0,58 \\
-0,62 \\
-0,12 \\
\text { Réf. } \\
0,36 \\
\end{array}$ & $\begin{array}{c}0,35 \\
0,57 \\
0,46 \\
0,43 \\
0,76 \\
0,42 \\
-0,50 \\
-0,35 \\
-0,77 \\
-0,38 \\
\text { n.s. } \\
\text { Réf. } \\
0,50 \\
\end{array}$ & $\begin{array}{c}\text { n.s. } \\
0,33 \\
\text { n.s. } \\
\text { n.s. } \\
\text { n.s. } \\
\text { n.s. } \\
\text { n.s. } \\
\text { n.s. } \\
-0,43 \\
\text { n.s. } \\
\text { n.s. } \\
\text { Réf. } \\
-0,28 \\
-0,28\end{array}$ & $\begin{array}{c}\text { n.s. } \\
0,41 \\
\text { n.s. } \\
0,23 \\
0,32 \\
\text { n.s. } \\
-0,35 \\
\text { n.s. } \\
-0,49 \\
\text { n.s. } \\
0,17 \\
\text { Réf. } \\
0,29 \\
\end{array}$ & $\begin{array}{c}\text { n.s. } \\
\text { n.s. } \\
-0,16 \\
\text { n.s. } \\
\text { n.s. } \\
\text { n.s. } \\
\text { n.s. } \\
0,03 \\
-0,37 \\
-0,24 \\
\text { n.s. } \\
\text { Réf. } \\
0,14\end{array}$ & $\begin{array}{c}\text { n.s. } \\
0,33 \\
\text { n.s. } \\
0,16 \\
0,30 \\
\text { n.s. } \\
-0,20 \\
\text { n.s. } \\
-0,46 \\
\text { n.s. } \\
\text { n.s. } \\
\text { Réf. } \\
0,25 \\
\end{array}$ \\
\hline
\end{tabular}

1. Pour les chômeurs et au foyer, même département (situation de référence) ou département différent.

n.s. : écart à la situation de référence non significatif au seuil de 0,05 .

Source : Échantillon démographique permanent, Insee. 